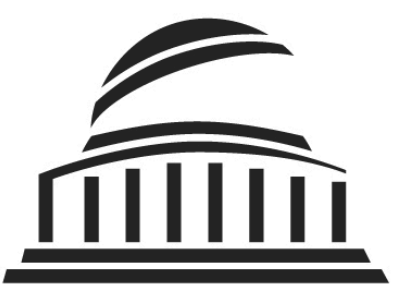

MIT
Open Access Articles

\title{
Material Viscoelastic Properties Modulate the Mesenchymal Stem Cell Secretome for Applications in Hematopoietic Recovery
}

The MIT Faculty has made this article openly available. Please share how this access benefits you. Your story matters.

\begin{tabular}{|l|l|}
\hline As Published & $10.1021 /$ ACSBIOMATERIALS.7B00644 \\
\hline Publisher & American Chemical Society (ACS) \\
\hline \hline Version & Author's final manuscript \\
\hline Citable link & https://hdl.handle.net/1721.1/134857 \\
\hline Terms of Use & $\begin{array}{l}\text { Article is made available in accordance with the publisher's } \\
\text { policy and may be subject to US copyright law. Please refer to the } \\
\text { publisher's site for terms of use. }\end{array}$ \\
\hline
\end{tabular}




\title{
Material Viscoelastic Properties Modulate the Mesenchymal Stem Cell Secretome for Applications in Hematopoietic Recovery
}

\author{
Frances D. Liu, ${ }^{\dagger, \ddagger}$ Novalia Pishesha, ${ }^{\dagger, \S}$ Zhiyong Poon, ${ }^{\ddagger}$ Tanwi Kaushik, ${ }^{\ddagger}$ and Krystyn J. Van Vliet ${ }^{*}$, ,,$\|_{\odot}$ \\ ${ }^{\dagger}$ Department of Biological Engineering, Massachusetts Institute of Technology, Cambridge, Massachusetts 02139, United States \\ ${ }^{\ddagger}$ BioSystems and Micromechanics (BioSyM) Interdisciplinary Research Group, Singapore-MIT Alliance for Research and \\ Technology, CREATE, Singapore 138602 \\ ${ }^{\S}$ Whitehead Institute for Biomedical Research, Cambridge, Massachusetts 02139, United States \\ "Department of Materials Science and Engineering, Massachusetts Institute of Technology, Cambridge, Massachusetts 02139, United \\ States
}

Supporting Information

\begin{abstract}
Human mesenchymal stem cells (MSCs) exhibit morphological and phenotypic changes that correlate with mechanical cues presented by the substratum material to which those cells adhere. Such mechanosensitivity has been explored in vitro to promote differentiation of MSCs along tissue cell lineages for direct tissue repair. However, MSCs are increasingly understood to facilitate indirect tissue repair in vivo through paracrine signaling via secreted biomolecules. Here we leveraged cell-material interactions in vitro to induce human bone marrow-derived MSCs to preferentially secrete factors that are beneficial to hematopoietic cell proliferation. Specifically, we varied the viscoelastic properties of cell-culture-

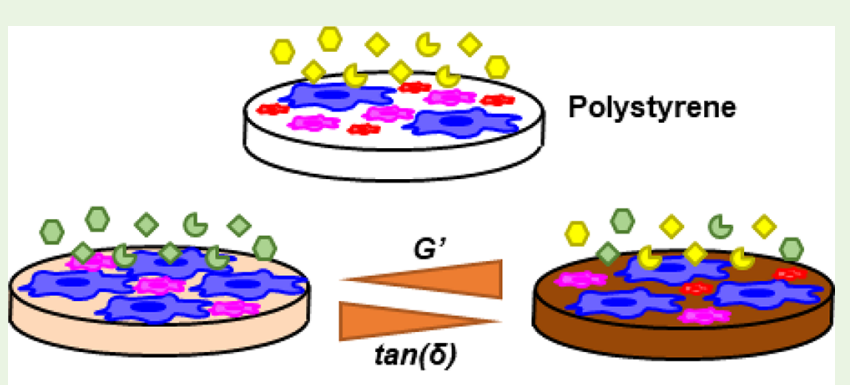

Tunable Polydimethylsiloxane compatible polydimethylsiloxane (PDMS) substrata to demonstrate modulated MSC expression of biomolecules, including osteopontin, a secreted phosphoprotein implicated in tissue repair and regeneration. We observed an approximately 3-fold increase in expression of osteopontin for MSCs on PDMS substrata of lowest stiffness (elastic moduli $<1 \mathrm{kPa}$ ) and highest ratio of loss modulus to storage modulus $(\tan (\delta)>1)$. A specific subpopulation of these cells, shown previously to express increased osteopontin in vitro and to promote bone marrow recovery in vivo, also exhibited up to a 5-fold increase in osteopontin expression when grown on compliant PDMS relative to heterogeneous MSCs on polystyrene. Importantly, this mechanically modulated increase in protein expression preceded detectable changes in the terminal differentiation capacity of MSCs. In coculture with human CD34+ hematopoietic stem and progenitor cells (HSPCs) that repopulate the blood cell lineages, these mechanically modulated MSCs promoted in vitro proliferation of HSPCs without altering the multipotency for either myeloid or lymphoid lineages. Cytokine and protein expression by human MSCs can thus be manipulated directly by mechanical cues conferred by the material substrata prior to and instead of tissue lineage differentiation. This approach enables enhanced in vitro production of both mesenchymal and hematopoietic stem and progenitor cells that aid regenerative clinical applications.
\end{abstract}

KEYWORDS: human mesenchymal stem cells, secretome, cell-material interactions, osteopontin, hematopoiesis, bone marrow regeneration

\section{INTRODUCTION}

Mesenchymal stem cells (MSCs) are nonhematopoietic stem cells that can be obtained as a subset of bone marrow stromal cells. ${ }^{1}$ As MSCs can be induced in vitro to differentiate along osteogenic, adipogenic, and chondrogenic lineages, ${ }^{2}$ these cells have long been considered for in vitro organoids, tissueengineered constructs, or cell therapies designed for direct tissue repair. ${ }^{3,4}$ These direct repair mechanisms would proceed in vivo presumably via MSC homing, engraftment, and differentiation into cell types required of the damaged tissue. ${ }^{5-8}$ Indeed, most in vitro studies have focused on mechanical modulation of phenotypic lineage commitment, e.g., via population-level expression correlated with differentiation along at least one mesenchymal tissue cell lineage, as a function of elastic modulus or stiffness of the materials to which the MSCs adhered. ${ }^{9-14}$ Nevertheless, in vivo studies of systemically administered MSCs have demonstrated repair following local injury due to thrombotic stroke, ${ }^{15,16}$ myocardial infarction, ${ }^{17-19}$ and bone marrow irradiation. ${ }^{20}$ However, tissue repair can occur in some contexts even when MSC engraftment and differentiation are not detectable, ${ }^{20}$ and evidence for robust MSC differentiation at the injury sites remains a point of

Received: September 1, 2017

Accepted: October 8, 2017

Published: October 8, 2017 
debate. $^{20-24}$ Such studies suggest that MSCs can play an important indirect repair role via paracrine signaling through secretion of immunomodulatory and pro-angiogenic cytokines to recruit and promote other cell types to repair the stroma of the injured tissue. ${ }^{25-33}$ Thus, there is growing interest in characterizing and manufacturing MSCs-in contrast to the progenitor or lineage-committed cells derived from MSCs-as a vehicle for indirect repair of bone marrow, neurological disorders, cardiovascular disease, liver failure, and immune disorders. $^{24,25,29,34-40}$

In our own work, we have exploited the indirect repair mechanisms of MSCs to support hematopoietic recovery in vivo. $^{20}$ MSCs constitute a heterogeneous population of cells, at least upon in vitro expansion conditions employed typically for bench-scale research or clinical administration of adult human bone marrow-derived MSCs. This emergent population heterogeneity results in multiple subpopulations of mesenchymal stromal cells that differ in biophysical, in vitro, and in vivo properties ${ }^{41-43}$ despite undetectable changes in proposed immunophenotypic markers of stemness by the International Society for Cellular Therapy. ${ }^{44}$ We leveraged microfluidic sorting to enrich cell-diameter-defined subpopulations of these mesenchymal stromal cells, ${ }^{41,45}$ effectively separating human MSCs from osteochondral progenitors of more restricted differentiation potential. This osteochondral progenitor subpopulation, defined in part by its relatively larger cell diameter ( $D^{h i}$ cells $),{ }^{41}$ homed to and promoted in vivo repair of the bone marrow compartment postirradiation without sustained engraftment. ${ }^{20}$ That subpopulation secreted increased concentrations of growth factors and cytokines known to promote hematopoietic recovery (e.g., ANG-1, BMP2, IL-8, and VEGF-A) and was consistent with prior reports of osteoblastlike cells or osteoprogenitors priming and organizing the hematopoietic microenvironment for hematopoiesis. ${ }^{4-49}$ Moreover, MSCs are not known to differentiate into or repopulate the hematopoietic cell lineages of the bone marrow, which is generally attributed instead to proliferation and differentiation of hematopoietic stem and progenitor cells (HSPCs). Those findings support the concept that putative MSCs-more accurately described as multipotent mesenchymal stromal cells or as MSC-derived progenitors-can promote bone marrow repair indirectly by acting as "cellular factories" that produce secreted factors promoting HSPC growth and differentiation (see the Supporting Information (SI) for further discussion).

Obtaining sufficient numbers of these microfluidically isolated MSC-derived osteochondral progenitors, or $D^{\text {hi }}$ cells of larger diameter $(\sim 20 \mu \mathrm{m})$, is inefficient because these cells constitute $<20 \%$ of the total culture-expanded MSC population, which ranges in diameter from 10 to $50 \mu \mathrm{m} .{ }^{20}$ In this work, we aimed to bias the heterogeneous population of MSCs toward the $D^{\text {hi }}$ cell phenotype, at least in terms of functional indicators such as secreted factors. This allowed us to circumvent the physical sorting that would reduce the yield of cultureexpanded cells for potential therapeutic indications. Thus, we leveraged microenvironment mechanical cues presented by the substratum material to modulate the MSC population toward secretome expression that could support hematopoietic recovery.

MSCs can also exert mechanical force on extracellular materials and, like many adherent cell types, exhibit mechanosensitive morphology and behavior. Prior studies have focused chiefly on how stiffness and topography of the material to which the cells adhere can modulate cell morphology and in vitro differentiation along mesenchymal tissue lineages of bone, cartilage, and fat. ${ }^{9-14,50-53}$ Such mechanotransduction occurs through extracellular matrix binding, chiefly via integrin-ligand interactions, ${ }^{54,55}$ and subsequent intracellular signaling, including chromatin remodeling, $^{56-59}$ and changes in transcription. ${ }^{60-62}$ Mechanical regulation of cell-generated forces and ligand-receptor interactions at the cell-material interface, intracellular cytoskeletal organization and signaling, and transcriptional activation have each been explored in relation to stem cell differentiation potential. ${ }^{54-62}$ Others have also reported correlations among viscoelastic time constants and MSC spread area and differentiation. ${ }^{53,63}$ For example, a recent study demonstrated that time scale of stress relaxation rather than changes in elastic modulus is correlated with changes in cell spreading and MSC differentiation. ${ }^{53,63}$ Whether and how the mechanical stiffness or stress relaxation of a material substratum causes (or simply correlates with) MSC lineage commitment in vitro remains an important clarification of active study. ${ }^{64-66}$ Such understanding can be aided by the use of cell culture materials for which mechanical and chemical properties can be varied widely and characterized quantitatively. Beyond heterogeneity of the culture-expanded cell population, the topography and surface chemistry of the material surface (including extracellular matrix ligand type, density, and configurational flexibility) can also modulate cell response or even act as the dominant cue. This coupling may conflate the effective stiffness of the ligand tether ${ }^{52,67,68}$ with that of the bulk or film material. ${ }^{64,66,69}$ Those prior studies prompt care in both design and characterization of the substratum surface and bulk properties when the goal is to determine the correlation of mechanical cues with MSC response. In contrast to these prior studies that varied mechanical or topographical properties to mimic aspects of tissue microenvironments, here we use mechanical cues to modulate the MSCs toward a therapeutically effective phenotype

Mechanical regulation of the MSC-secreted factors, or secretome prior to terminal differentiation and lineage commitment of the cell population has been largely neglected. Multiple translational applications of MSCs do not anticipate or require in vivo differentiation of these cells into adipocytes, chondrocytes, or osteoblasts but do require the capacity to produce large numbers of those cells in vitro with predictable therapeutic efficacy and cost efficiency. Thus, we focus here on mechanical modulation of the MSC secretome prior to detectable terminal differentiation of the population. We show that viscoelastic properties of the adherent substratum material can alter or bias a heterogeneous population of MSCs to a phenotype that can stimulate bone marrow repair, including HSPC proliferation and commitment in vitro. This mechanical priming of MSCs is advantageous even when cells can be sorted (via biophysical or biochemical markers) in that the targeted subpopulations of such label-free sorting typically constitute $<20 \%$ of the starting cell population. ${ }^{41}$ These findings demonstrate how cell-material interactions in vitro can be engineered to more efficiently produce an MSC-derived cell population for in vitro HSPC production or for in vivo hematopoietic recovery.

\section{MATERIALS AND METHODS}

2.1. Material Formulation and Mechanical Characterization. Mechanically tuned cell culture substrata were fabricated from 
commercially available two-component polydimethylsiloxane (PDMS) (CY 52-276, Dow Corning). This particular PDMS formulation was selected instead of the more commonly used Sylgard 184 (Dow Corning) formulations used by others ${ }^{64,66}$ because fully cured polymers with low elastic moduli $(<100 \mathrm{kPa})$ were more reliably attained with this $\mathrm{CY}$ two-component system. Distinct viscoelastic (mechanical) properties were obtained via systematic variation the ratio of the two components, a prepolymer base and cross-linking catalyst (parts A and B, respectively). PDMS mixtures with specific $\mathrm{A}: \mathrm{B}$ ratios were cured for $24 \mathrm{~h}$ at $80{ }^{\circ} \mathrm{C}$ in air.

The shear storage and loss moduli ( $G^{\prime}$ and $G^{\prime \prime}$, respectively) were measured in the linear viscoelastic range via parallel-plate shear rheometry (Anton Paar, $10 \mathrm{~mm}$-diameter plate) at $1 \%$ strain from 0.1 to $100 \mathrm{rad} / \mathrm{s}$. The linear viscoelastic range was determined by conducting an amplitude sweep from $0.01 \%$ to $10 \%$ strain at $1.6 \mathrm{~Hz}$ $(10 \mathrm{rad} / \mathrm{s})$. The linear viscoelastic range was determined to be about $\sim 0.5 \%$ to $\sim 10 \%$ strain (see the SI and Figure S1). Components A and $B$ were varied in mass ratios of $3: 2,1: 1$, and 1:3 to obtain materials with shear storage moduli $G^{\prime}(1 \mathrm{~Hz})$ of approximately 1,10 , and 100 $\mathrm{kPa}$, respectively.

2.2. PDMS Culture Surface Preparation and Characterization. Premixed PDMS liquids $(0.2 \mathrm{~mL})$ were aliquotted directly into wells of $2.2 \mathrm{~cm}$ diameter (within a 12-well plate); this fluid volume resulted in PDMS substrata with an approximate thickness of $\sim 500 \mu \mathrm{m}$ after curing. One column of wells was left blank to serve as a control (non-PDMS) substratum comprising tissue-culture-treated polystyrene (PS). Immediately after PDMS curing, the plates were plasma-treated for 5-10 min to render PDMS surfaces sufficiently hydrophilic for tissue culture. In contrast to prior recent studies, ${ }^{64,66}$ these PDMS surfaces were neither further treated nor covalently functionalized prior to addition of cells and were rendered sufficiently hydrophilic and cytophilic by this surface treatment as described previously. ${ }^{70}$ The only extracellular matrix proteins present on the PDMS would be nonspecifically adsorbed serum proteins or those secreted by the cells themselves. In a separate experiment described in the SI, PDMS surfaces were also modified to explore the effects of binding a specific protein.

The following characterizations (Figure 1D,E) were performed to determine various surface properties that might affect the cell-material interactions. Surface wettability was determined via water contact angle measurements in air (VCA200). The contact angle was measured before and immediately after plasma treatment of the PDMS substrata. Contact angle measurements of the surfaces were also obtained 1,2, and 3 days after exposure to air in order to evaluate the time required before the cell culture substrata become distinct as a result of hydrophobic recovery.

To determine the degree of nonspecific protein adsorption, small volumes $(0.2 \mathrm{~mL})$ of fetal bovine serum (FBS) (Gibco, 16000-044) were deposited immediately into wells after plasma treatment and incubated for $2 \mathrm{~h}$ at $37^{\circ} \mathrm{C}$. Nonadsorbed serum was aspirated, and the surfaces were washed twice with $150 \mathrm{mM} \mathrm{NaCl}$ phosphate-buffered saline (PBS). Adsorbed proteins were then released with $0.05 \%$ Trypsin-EDTA (Gibco, 25300062), and fluorescently stained using the Qubit Protein Assay Kit (ThermoFisher Scientific, Q33211). Total protein was then assessed via fluorimetry using the Qubit (Qubit 2.0, Thermo Fisher Scientific).

2.3. Cell Culture and Characterization. Human bone marrowderived MSCs (MSCs) were purchased from multiple commercial sources (Lonza, RoosterBio, and ReachBio) at what was stated by the vendors to be a low passage number. MSCs were isolated from healthy-donor-derived bone marrow aspirate. Cells were expanded in complete expansion medium containing low-glucose Dulbecco's modified Eagle's medium (DMEM) (Gibco, 11885-084), 10\% FBS, and $1 \%$ penicillin-streptomycin (pen-strep) (Gibco, 10378-016) in $5 \% \mathrm{CO}_{2}$ at $37{ }^{\circ} \mathrm{C}$ to passage 5-7 (up to approximately 14 population doublings) on commercial tissue-culture-treated polystyrene (Falcon, 353112) prior to plating in prepared PDMS wells. Expansion medium was added to culture wells $(1.0 \mathrm{~mL} /$ well $)$ immediately after plasma treatment to maintain the hydrophilic state of the substratum surfaces prior to the addition of MSCs at $\sim 1000$ cells $/ \mathrm{cm}^{2}$. Within each well, the medium was exchanged every 3-4 days for replacement with complete expansion medium, and cells were characterized at approximately day 7 .

Size-sorted subpopulations were obtained as described previously using an inertia-based spiral microfluidic device with a trapezoidal channel cross section and two outlets. ${ }^{20,41}$ This resulted in two cell subpopulations enriched from the heterogeneous, putative MSC population, characterized by a larger and smaller mean cell diameter in suspension. These sorted subpopulations were grown on PDMS substrata in the same way as heterogeneous, unsorted populations.

Cells were imaged in phase contrast (Olympus IX-81) in both the attached state and suspended (i.e., post-trypsinization) states to determine the cell spread area and suspended cell diameter, respectively. These geometric descriptors were obtained via image analysis with customized scripts in MATLAB and CellProfiler.

2.4. mRNA and Protein Expression. Culture-expanded MSCs were plated and grown on PDMS substrata as described above prior to analysis of mRNA expression. Cells were lysed for mRNA extraction after 1 week in culture. mRNA expression levels were determined using qRT-PCR (EXPRESS SYBR GreenER qPCR, Life Technologies). The $\Delta \Delta \mathrm{C}_{\mathrm{T}}$ method was used to quantify relative mRNA expression levels across samples. The primer sequences for glyceraldehyde 3-phosphate dehydrogenase (GAPDH), runt-related transcription factor 2 (RUNX2), osteopontin (OPN), osteocalcin $(\mathrm{OCN})$, peroxisome-proliferator-activated receptor gamma (PPAR $\gamma)$, and hyaluronan and proteoglycan binding link protein 1 (HAPLN) were the same as published previously. ${ }^{20}$ GAPDH was the reference gene for normalization of expression.

Cells were plated at a slightly higher density of $20000 \mathrm{cells} / \mathrm{cm}^{2}$ on PDMS (in a $60 \mathrm{~mm}$-diameter Petri dish format) prior to analysis of secreted protein via a multiplexed antibody panel. After 4-5 days in complete expansion culture medium, MSCs were serum-starved, and MSC-conditioned serum-free medium was harvested after 24-48 h. Samples of $0.5 \mathrm{~mL}$ each were concentrated 10-fold using Amicon Ultra-0.5 centrifugal filter units (Millipore, cat. no. UFC500324) to reduce the volume by 10 -fold to $50 \mu \mathrm{L}$. They were then assayed using a Bradford assay (Thermo Fisher Scientific, cat. no. 23236) to determine the total protein concentration. All of the total protein concentrations were divided by the minimum concentration within each set of samples to calculate a normalization factor to account for differences in cell number. The 10 -fold concentrated samples were then assayed in technical duplicates using the ProcartaPlex 45-plex human cytokine/cytokine/growth factor panel (eBioscience, EPX45012171-901) following the manufacturer's instructions. The concentrations reported in Figure 5 are 10-fold concentrated and divided by the normalization factor calculated from the Bradford assay.

Secreted ostepontin was analyzed via quantitative ELISA (eBioScience, BMS2066). Cells were plated at a density of 10000 cells $/ \mathrm{cm}^{2}$ and allowed to grow to confluence for $4-5$ days in culture. A smaller volume of $1.0 \mathrm{~mL} /$ well of fresh expansion medium was then added, and MSC-conditioned medium was harvested after another 45 days. The MSC-conditioned medium was used directly without dilution for ELISA quantification. ELISA was performed following the manufacturer's protocol.

2.5. MSC Osteogenic Induction and Quantification. Cells were plated into 12 -well plates at $25000-30000 \mathrm{cells} / \mathrm{cm}^{2}$ in expansion medium. After $24 \mathrm{~h}$, the expansion medium was exchanged for osteogenic induction medium (OIM), comprising high-glucose DMEM (Gibco, 11995-065), 10\% FBS, 1\% pen-strep, $10 \mathrm{mM} \beta$ glycerophosphate disodium salt hydrate (Sigma, G9422), $10 \mathrm{nM}$ dexamethasone (Sigma, D4902), and $0.2 \mathrm{mM}$ L-ascorbic acid 2phosphate sesquimagnesium salt (Sigma, A8960). Cells were induced in OIM for up to 1 week with OIM exchanges every 3-4 days.

Cells were fixed in $4 \%$ formaldehyde for $15 \mathrm{~min}$ at room temperature, and the wells were gently washed with deionized water between the fixing and staining steps. Cells were stained with Alizarin Red for $\sim 15-20$ min to identify mineral deposition, and then excess stain was rinsed. Stained mineral deposits were then completely dissolved with acetic acid, and those dissolved products were added to ammonium hydroxide in a new 96-well plate. Absorbance at a 

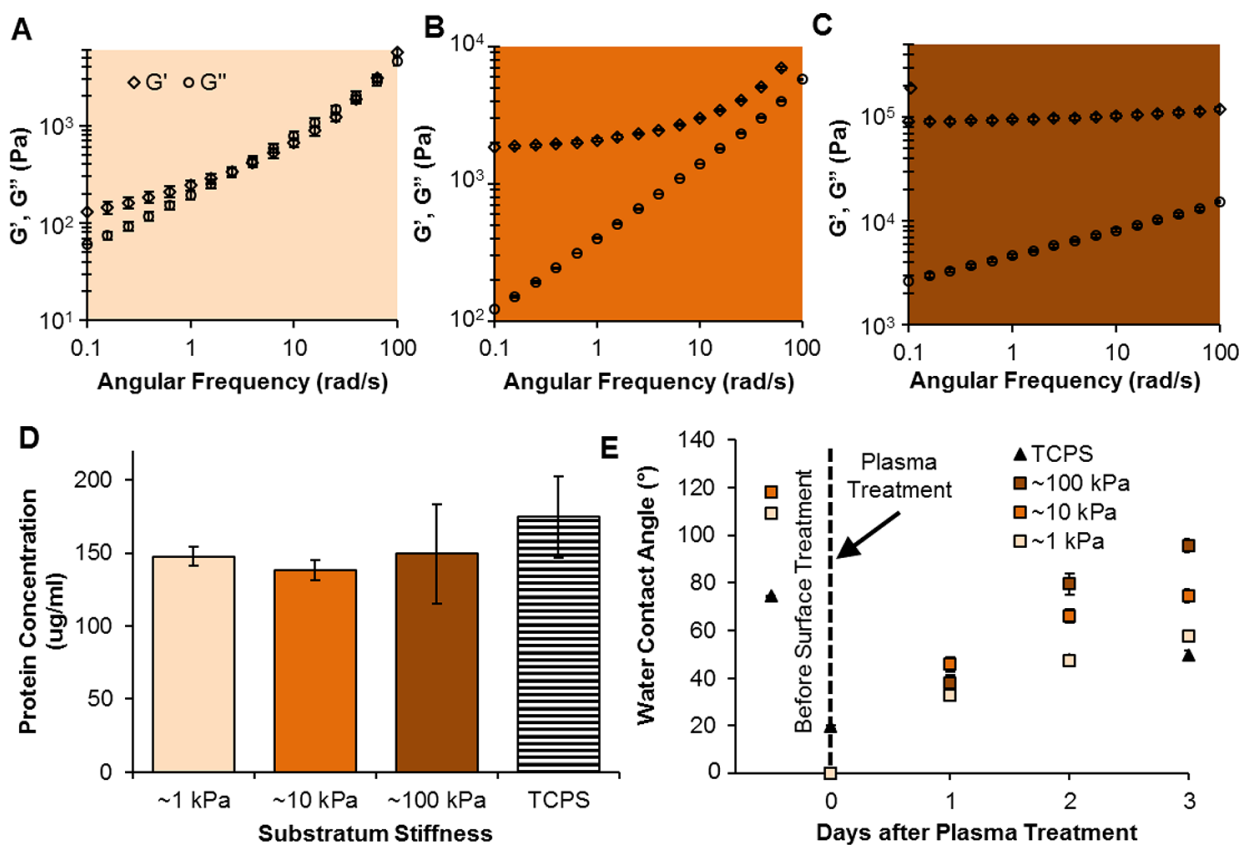

Figure 1. Mechanical and surface characterization of elastomeric substrata. (A-C) Frequency sweeps at $1 \%$ strain for PDMS gels of varying prepolymer to cross-linker composition: (A) 3:2, (B) 1:1, and (C) 1:3. The equilibrium shear storage modulus ranges across 3 orders of magnitude corresponding to $\sim 1 \mathrm{kPa}, \sim 10 \mathrm{kPa}$, and $\sim 100 \mathrm{kPa}$. (D) Concentration of nonspecific serum protein adsorption to the substrata after incubation for 2 h. (E) Surface wettability as determined using water contact angle measurements in air before and after plasma oxidation of cell culture substrata.

wavelength of $405 \mathrm{~nm}$ (Tecan Infinite 200 Pro) was quantified in the 96-well plate to compare extents of mineral deposition.

2.6. HSPC/MSC Coculture. Mobilized bone marrow CD34+ cells, i.e., human hematopoietic stem and progenitor cells (HSPCs) (the Fred Hutchinson Cancer Center), were cocultured with human MSCs. MSCs were first added to 24-well plates with PDMS substrata (or tissue-culture-treated PS controls), prepared as described above. MSCs were seeded onto PDMS and tissue-culture-treated PS wells at 10000 cells $/ \mathrm{cm}^{2}$ and allowed to grow for 4-5 days until full confluency on all substrata. Transparent, semipermeable cell culture inserts with $1.0 \mu \mathrm{m}$ pores (Falcon, 353103) were gently placed on top of MSC monolayers within each well to physically separate the HSPCs from the MSCs. The small pore size $(1.0 \mu \mathrm{m})$ ensured that there would be no contact between the HSPCs $(\sim 10 \mu \mathrm{m}$ mean diameter $)$ and MSCs $(\sim 20 \mu \mathrm{m}$ mean diameter) while still allowing for exchange of secreted cytokines and growth factors. HSPCs were then added on top of the semipermeable inserts at a density of 5000 HSPCs per well. Control conditions included PS wells seeded with MSCs and MSC-free PDMS wells containing only HSPCs as a representation of standard HSPC expansion conditions. Cocultures were grown in HSPC expansion medium containing $100 \mathrm{ng} / \mathrm{mL}$ recombinant human (rh) FLT3 9 (Peprotech, 300-19), 100 ng/mL rhSCF (Peprotech, 300-07), 20 ng/ $\mathrm{mL}$ rhIL6 (Peprotech, 200-06), $20 \mathrm{ng} / \mathrm{mL}$ rhIL3 (Peprotech, 200-03), and $100 \mathrm{nM}$ dexamethasone (Sigma-Aldrich, D2915) in Stemspan SFEM II medium for 7 days.

HSPCs were then harvested via aspiration, followed by collection of any remaining cells with two vigorous PBS washes and collections. The wells were visually inspected under phase contrast to ensure removal of all HSPCs from on top of the insets. HSPC proliferation was quantified using a Cellometer Auto T4 Cell Viability Counter (Nexcelom Bioscience) for all conditions. HSPCs were then prepared for flow cytometry analyses. Cells were washed once with PBS and resuspended in FACS buffer containing $2 \mathrm{mM}$ EDTA and 5\% FBS in PBS. Cells were then stained with anti-CD34-FITC (eBioscience, 110349-42), anti-CD10-Pe/Cy7 (BioLegend, 312214) and anti-CD123eFluor450 (eBioscience, 48-1238-42) for $30 \mathrm{~min}$ at $4{ }^{\circ} \mathrm{C}$. Samples were washed twice with FACS buffer prior to further analysis. All of the flow data were acquired on a FACS Fortessa flow cytometer (BD Biosciences) and analyzed using Flowjo software (Tree Star Inc.,
Ashland, OR). For contact coculture (see the SI), this method was followed except that no transwell inserts were added prior to seeding with HSPCs.

\section{RESULTS}

3.1. Characterization of Bulk and Surface Properties of Cell Culture Substrata. Figure 1A-C shows that the three compositions of silicone materials used as MSC substrata differed substantially in viscoelastic properties. We varied these mechanical properties-spanning 3 orders of magnitude in shear storage modulus $G^{\prime}$-via systematic variation in the extent of cross-linking while otherwise maintaining constant chemical composition within the silicone elastomer used as the cell culture substratum. ${ }^{66}$ Polydimethylsiloxane (PDMS) is a nonporous elastomer that provides a wide range of mechanical stiffness without conflating differences in ligand tethering spacing or flexibility, as may occur with other material systems such as relatively porous hydrogels. ${ }^{66}$ As most reported studies consider only the linear elastic modulus of viscoelastic polymers used as cell culture substrata, we also report a single $G^{\prime}$ as a measure of mechanical stiffness for each of the three PDMS formulations used. We approximated $G^{\prime}$ at $1 \%$ strain and $1 \mathrm{~Hz}$ strain frequency for these three materials within the linear elastic regime, hereafter denoted as 1,10 , and $100 \mathrm{kPa}$. The viscoelastic damping factor (i.e., the ratio of the shear loss modulus to the shear storage modulus, $\tan (\delta)=G^{\prime \prime} / G^{\prime}$ ) also differed substantially among these materials (see the SI and Figure S2A).

Despite this wide variation in mechanical characteristics, we detected no significant differences in the extent of extracellular matrix protein adsorption (Figure 1D) or water contact angle, which describes the wettability or hydrophilicity (Figure 1E), among these PDMS substrata. All of the PDMS substrata were rendered equally hydrophilic immediately after plasma oxidation and were more hydrophilic than tissue-culture-treated polystyrene (PS). This hydrophilicity decreased to levels 
A

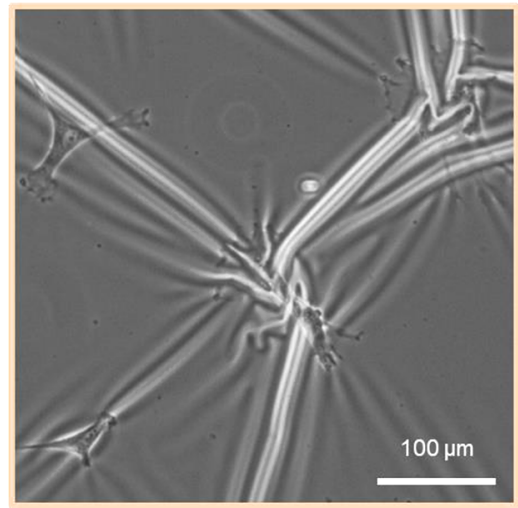

B

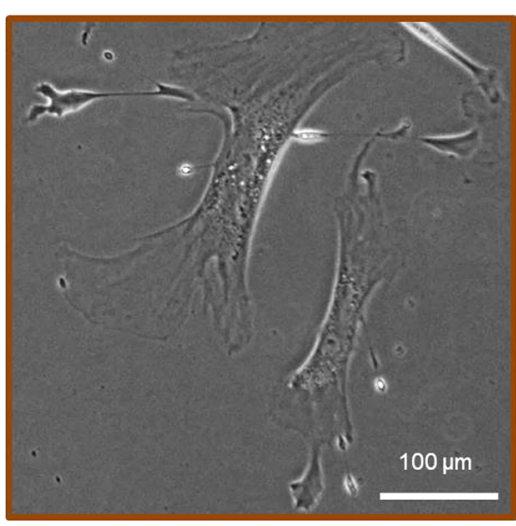

C

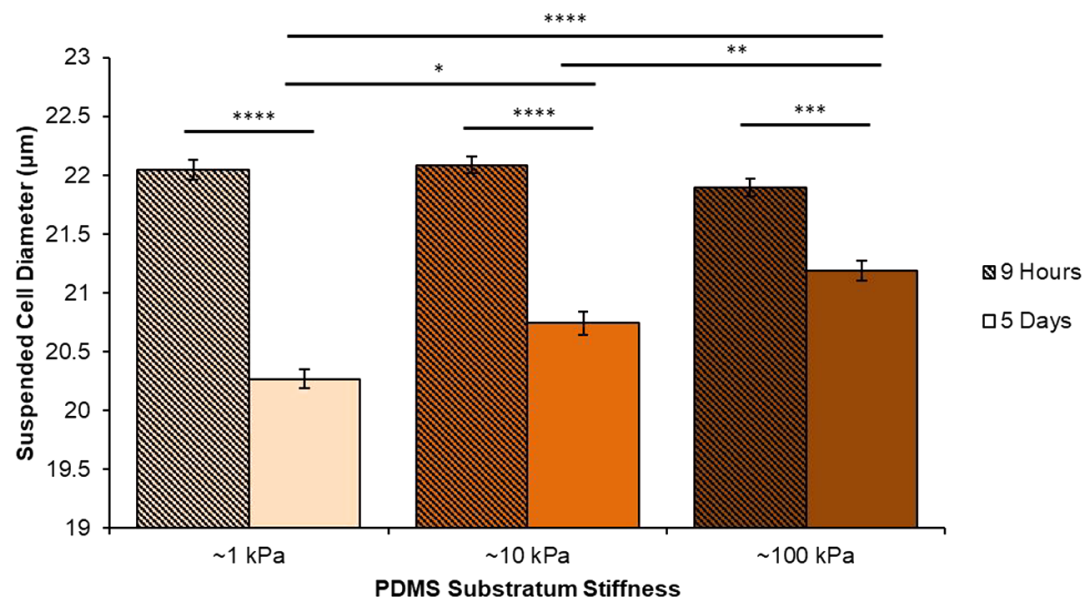

Figure 2. Cell size changes in response to PDMS substrata. (A, B) Phase contrast images of hMSCs grown on PDMS of varying viscoelastic properties corresponding to increasing shear storage modulus ( $\sim 1 \mathrm{kPa}$ and $\sim 100 \mathrm{kPa}$, respectively). (C) Geometric mean \pm geometric SEM of suspended cell diameter determined on substrata of varying stiffness. The suspended cell diameter was determined by trypsinization and image analysis (striped bars) $9 \mathrm{~h}$ and (solid bars) 5 days after seeding of cells on substrata. Statistical differences in expression were determined using the unpaired two-tailed Student's $t$ test with unequal variance $\left(*, p<0.0005 ; * *, p<0.0001\right.$; ***, $\left.p<1 \times 10^{-9} ; * * * *, p<5 \times 10^{-15}\right)$.

commensurate with that of PS within 1 day of storage in air, defining the optimal storage duration of such materials. After air exposure for 1 day, PDMS substrata became equally hydrophilic as tissue-culture-treated PS. This suggests that the PDMS substrata can be used for up to 1 day after plasma treatment.

It should be noted that we included tissue-culture-treated PS as an experimental control representing the current standard substratum for in vitro expansion of MSCs and MSC/HSPC coculture. This condition is indicated as black points or striped bars in all of the figures (e.g., Figure 1D,E) to make clear that we do not include this ubiquitous cell substratum material in our consideration of substrata mechanical effects. Polystyrene is a glassy polymer that is orders of magnitude stiffer than these PDMS materials $(\sim 1 \mathrm{GPa})^{71}$ and also differs significantly from PDMS in surface topography and chemistry, which can also act as cues to adherent cells.

\subsection{Cell-Material Interactions and Changes in Cell}

Size. Figure 2 shows that cells adhered to and exerted force against the PDMS substrata and that the mean cell size increased slightly on stiffer substrata. The cell-generated force was sufficient to induce surface wrinkling visible via phase contrast for cells adhered to the more compliant substrata (Figure $2 \mathrm{~A}$ for $1 \mathrm{kPa}$ and Figure $\mathrm{S} 5$ for $10 \mathrm{kPa}$ ). The apparent cell spread area was larger but wrinkling was not detectable on the stiffest of these PDMS substrata (Figure 2B, $100 \mathrm{kPa}$ ). We verified that surface wrinkling on the PDMS was cell-induced, as we observed no changes in the surfaces of the PDMS substrata prior to cell attachment (Figure S4). We compared cell sizes shortly after cell adhesion $(9 \mathrm{~h})$ and after population doublings ( 5 days) on each material in terms of suspended cell diameter immediately upon trypsinization. We detected no significant differences in cell size within $9 \mathrm{~h}$ after seeding (Figure 2C), indicating that larger cells did not preferentially attach to the stiffer substrata. However, cell progeny at day 5 exhibited larger diameters on stiffer substrata (Figure 2C). Although this increase in geometric mean cell diameter was statistically significant $\left(p<5 \times 10^{-15}\right.$ comparing substrata of 1 to $100 \mathrm{kPa}$ stiffness), the cell diameters were greater by only 1 $\mu \mathrm{m}(5 \%)$ on the stiffest compared with the most compliant substrata. (See SI section 5 and Figure S6 for further descriptors of the cell diameter distribution on PDMS substrata.) As conveyed in the Discussion, this slight but detectable difference in mean cell diameter was an order of magnitude less than differences between the mean cell diameters of physically sorted MSC subpopulations.

3.3. Viscoelastic Moduli Correlated with Changes in MSC Expression. More importantly, these changes in substrata stiffness also correlated with changes in mRNA and protein expression by MSCs prior to detectable changes in terminal phenotypic differentiation along the osteogenic pathway. We considered mRNA expression changes via quantitative polymerase chain reaction (qPCR) for markers 
A

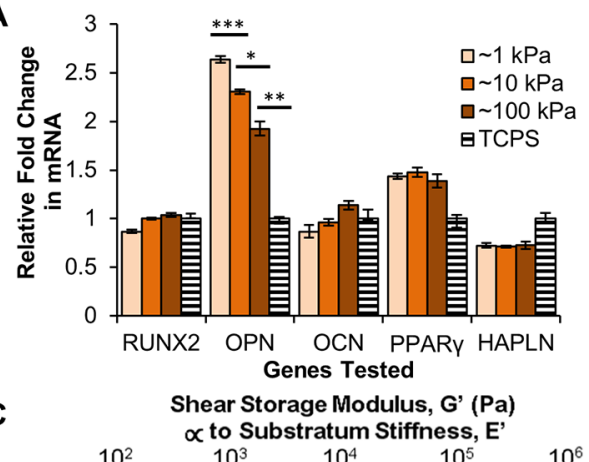

B

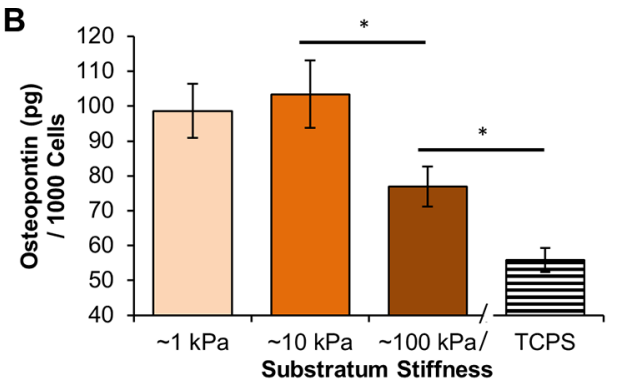

D

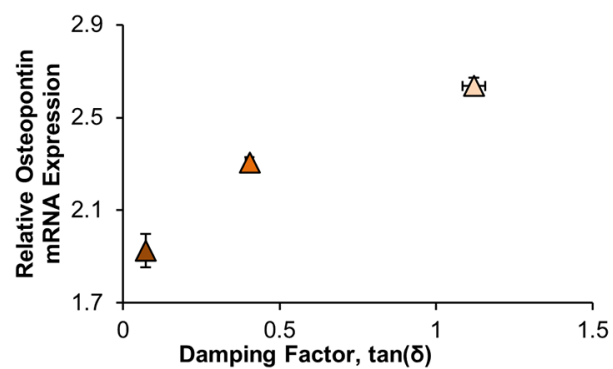

$\propto$ to Substratum Viscous Dissipation, E"

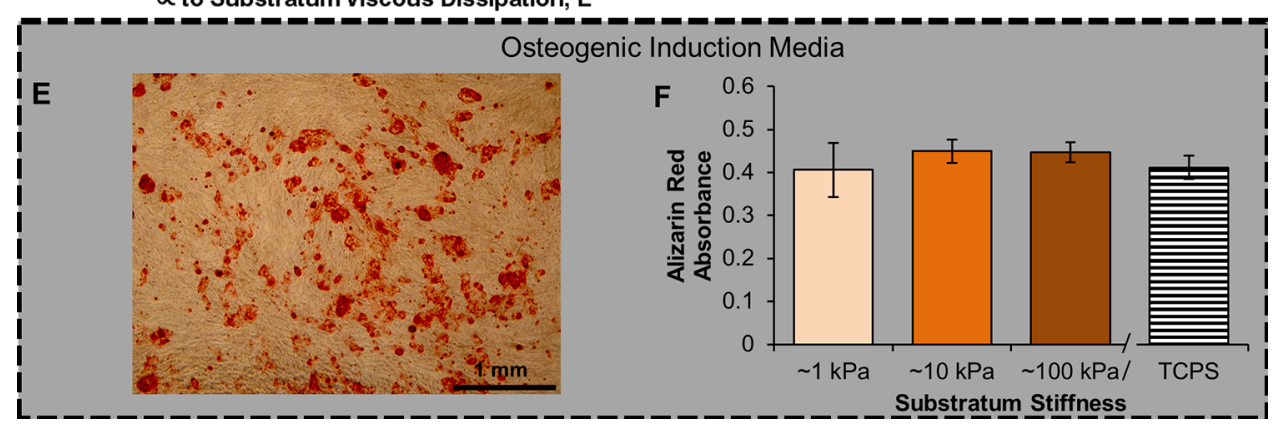

Figure 3. Biological response of unsorted MSCs on elastomeric substrata. (A) After 1 week in culture, cells were lysed, and RNA was extracted and analyzed. The first three genes are osteogenic markers (RUNX2, OPN, OCN), the fourth gene is a chondrogenic marker (HAPLN), and the last gene is an adipogenic marker (PPAR $\gamma$ ). The $\Delta \Delta \mathrm{C}_{\mathrm{T}}$ method was used for relative quantification of expression levels from $\mathrm{qRT}$-PCR with normalization to expression levels of hMSCs grown on polystyrene (black striped bars); error bars represent standard deviations. Statistical differences in expression were determined using the unpaired, two-tailed Student's $t$ test with unequal variance $(*, p<0.005 ; * *, p<0.001 ; * * *, p<$ 0.0005). (B) Mean osteopontin protein measured via ELISA with error bars representing standard deviation $(*, p<0.05)$. (C, D) Relative osteopontin mRNA expression as a function of (C) the shear storage modulus $G^{\prime}$ (top horizontal axis) and shear loss modulus $G^{\prime \prime}$ (bottom horizontal axis) and (D) the damping factor $\left(\tan (\delta)=G^{\prime \prime} / G^{\prime}\right) . G^{\prime}, G^{\prime \prime}$, and $\tan (\delta)$ were determined at a shear oscillation frequency of $\sim 1 \mathrm{~Hz}(\sim 6.31$ $\mathrm{rad} / \mathrm{s}$ ). Error bars represent standard deviations. (E) Representative image of an Alizarin Red-stained MSC monolayer grown in the presence of osteogenic induction medium for 1 week. Alizarin Red stains for calcium deposits secreted by osteogenic MSCs. (F) Mineral deposition quantified using absorbance of dissolved Alizarin Red stain.

of adipogenesis (peroxisome-proliferator-activated receptor gamma, PPAR $\gamma$ ) and chondrogenesis (hyaluronan and proteoglycan link protein 1, HAPLN) as well as markers for osteogenesis spanning early- to later-stage commitment: runtrelated transcription factor 2 (RUNX2, early), ostepontin (OPN, mid), and osteocalcin (OCN, late). Expression of RUNX2, OCN, PPAR $\gamma$, and HAPLN did not vary significantly with substratum stiffness relative to expression on tissueculture-treated PS. To detect the formation of osteochondral progenitors $\left(D^{\text {hi }}\right.$ cells), we also paneled multiple chondrogenic markers but saw no correlations between expression of any chondrogenic marker and substratum stiffness (Figure S9). However, Figure 3A shows that OPN expression increased with decreasing PDMS stiffness, with a $>2.5$-fold increase on the most compliant substrata.

MSCs also exhibited upregulated osteopontin expression at the protein level as detected via ELISA, with up to a 2 -fold increase in secreted osteopontin for cells on PDMS (Figure 3B) compared with tissue-culture-treated PS. Maximum expression of secreted osteopontin occurred on PDMS of intermediate stiffness $(10 \mathrm{kPa})$, indicating a biphasic rather than monotonic correlation with substratum stiffness. This increase in osteopontin expression by MSCs on PDMS correlated with increasing shear storage modulus $G^{\prime}$, which is proportional to the substratum stiffness, and also with the viscoelastic properties of the substratum material. For example, relative osteopontin expression increased with decreasing shear loss modulus $G^{\prime \prime}$ (Figure 3C) and increased with increasing damping factor of the material, $\tan (\delta)$ (Figure 3D). However, we detected no difference in the extent of terminal osteogenic differentiation as a function of substratum stiffness at day 7 (Figure 3E,F) upon chemical induction of osteogenesis and Alizarin Red staining and quantification of mineral deposits. Taken together, these data show a significant stiffnesscorrelated increase in osteopontin production as a function of PDMS substrata stiffness and other viscoelastic parameters 
A Heterogeneous MSCs (CTRL)

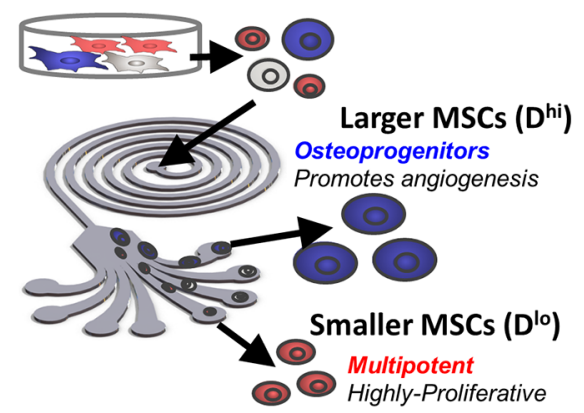

B

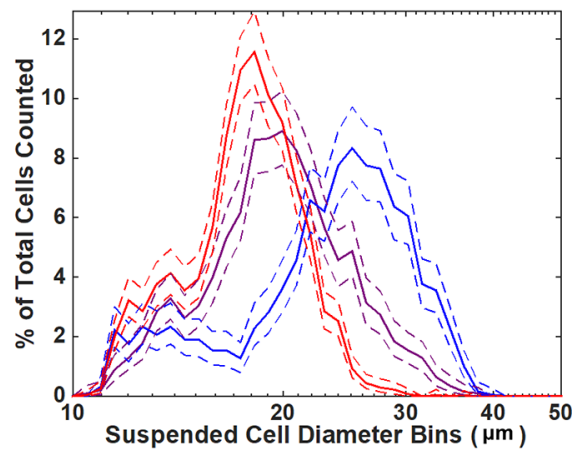

D
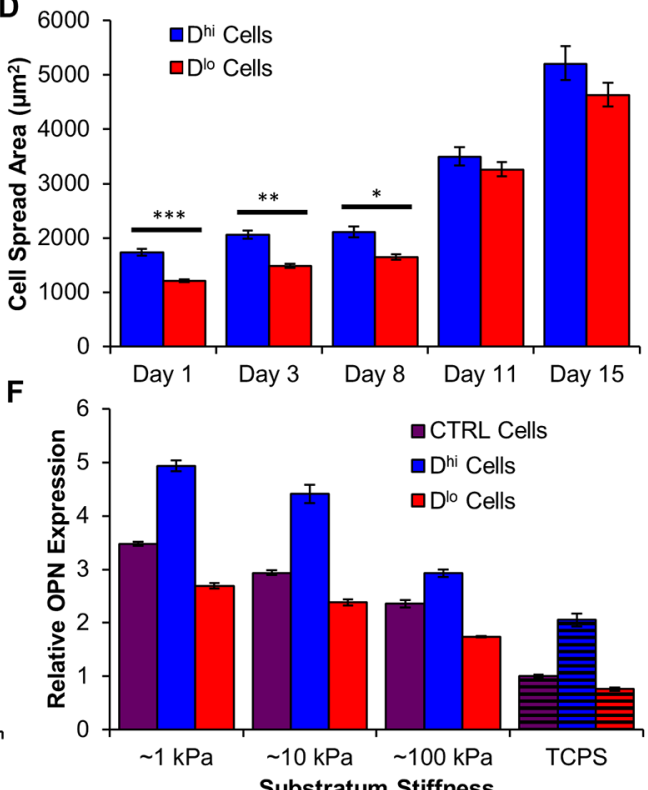

Figure 4. Size-sorted MSC subpopulations. (A) Schematic diagram of the inertial spiral microfluidic device used for size-based sorting of hMSCs. Blue cells represent large cells $\left(D^{\mathrm{hi}}\right)$, red cells represent small cells $\left(D^{\mathrm{lo}}\right)$, and gray cells represent intermediate-sized cells. CTRL cells (purple) are a heterogeneous, unsorted cell population. (B, C) Typical size distributions of sorted cells represented as (B) a log-distributed histogram with $\pm 95 \%$ bootstrapped confidence intervals delineated with dotted lines and (C) a bar chart representing the geometric mean of the suspended cell diameter with error bars representing the geometric SEM. (D) Tracking of the geometric mean of attached cell spread areas of sorted cells over the course of 2 weeks $\left(*, p<5 \times 10^{-5} ; *, p<5 \times 10^{-12}\right.$; ***, $\left.p<1 \times 10^{-20}\right)$, showing that the sorted cell fractions remain statistically distinct in size after 1 week in culture on polystyrene (PS). Error bars represent geometric SEM. Statistical differences in expression were determined using the unpaired two-tailed Student's $t$ test with unequal variance. (E) Large vs small cell relative expression of genes correlated with bone marrow recovery after growth on PS for 1 week. (F) Relative osteopontin expression of the unsorted (magenta) and sorted (blue and red) cell populations after 1 week in culture on PDMS susbtrata of varying stiffness $(\sim 1 \mathrm{kPa}, \sim 10 \mathrm{kPa}, \sim 100 \mathrm{kPa})$ and on PS ( 1 GPa; black striped bars). Error bars for expression data in (E) and (F) represent standard deviations.

within 1 week in vitro but not in late-stage markers or metabolic profiles indicative of osteogenic lineage commitment.

3.4. Mechanical Modulation of Isolated Subpopulations. We previously isolated and characterized ostechondral progenitors from a putative MSC population. ${ }^{20}$ Those osteochondral progenitors were distinguished by biophysical markers, including cell diameter, ${ }^{41}$ and efficiently separated from the heterogeneous population via inertial microfluidic sorting of the fluid-suspended cells (Figure 4A). ${ }^{20}$ These cells were the subset of putative MSCs that best supported indirect repair of the hematopoietic compartment in vivo, primarily through paracrine signaling and not engraftment. Because the osteochondral progenitor cells characterized through this biophysical sorting constituted $<20 \%$ of the heterogeneous population of MSCs, the available cell numbers were reduced drastically with respect to the total culture-expanded heterogeneous population. Osteopontin (OPN) is a secretome component and osteogenic differentiation marker that serves as a key marker for the osteochondral progenitors. Using OPN as a correlative marker for the therapeutically effective MSC phenotype, we then explored how PDMS substrata of varying mechanics could modulate both isolated MSC subpopulations and heterogeneous MSC populations. These experiments were designed to answer the following questions: (1) Can we further increase the expression of known cytokines from the osteochondral progenitors? (2) Can we bias the therapeutically ineffective subset of MSCs toward the osteochondral progenitor phenotype?

We thus enriched for osteochondral progenitors, resulting in a subpopulation with a mean cell diameter of $22.6 \mu \mathrm{m}$, approximately $5 \mu \mathrm{m}$ larger than that of the relatively smaller cells (Figure 4B,C). For brevity and to indicate that this sorted subset of larger diameter, $D^{\text {hi }}$, is not considered a stem cell population, these sorted groups derived from heterogeneous MSCs are designated hereafter as larger or $D^{\text {hi }}$ cells and smaller or $D^{\text {lo }}$ cells. We confirmed key baseline characteristics of the 


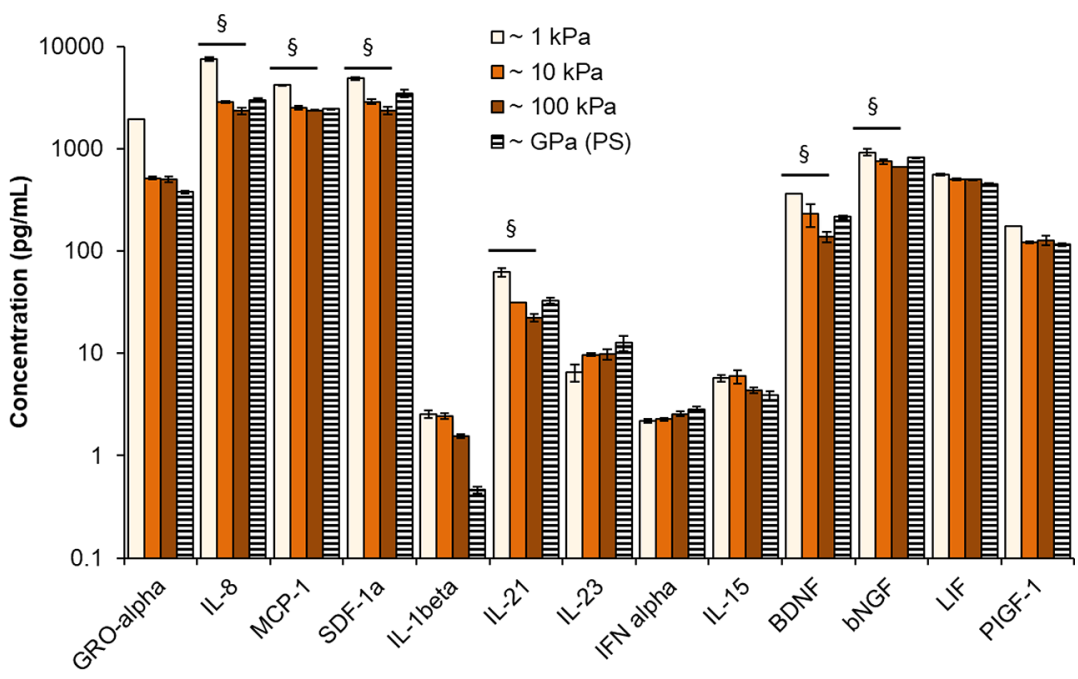

Figure 5. Secretome-wide changes on all substrata. Protein expression changes in the secretome were paneled using a multiplexed antibody array (ProcartaPlex Immunoassay 45-plex). Expression levels of secretome samples harvested from hMSCs grown on PDMS and PS are shown in orange bars and black-striped bars, respectively. Error bars represent standard deviations. Statistically significant trends on PDMS substrata only were determined by calculation of the Spearman correlation coefficient $\rho$ and its corresponding $p$ value ( ${ }^{\S}$, Spearman $|\rho|>0.8$ and $p<0.05$ ).

sorted larger cells subcultured on tissue-culture-treated PS for 1 week, a duration over which approximately two population doublings occurred. Cells of larger diameter also maintained a larger spread cell area for over 1 week in culture on tissueculture-treated PS (Figure 4D), the same duration over which cells were grown on our PDMS substrata. Thus, even when expanded for a week in culture, the cells remained distinct in relatively larger spread area indicative of cell size. These sorted $D^{\text {hi }}$ subpopulations expressed over 2 -fold more OPN than the unsorted population (labeled as the control) and 5-fold more OPN than the sorted subpopulation of smaller cell diameter (Figure 4E). In addition to greater expression of OPN, these larger cells also exhibited greater expression of other cytokines that participate in immune regulation and hematopoietic support, such as interleukin 8 (IL-8) and insulin-like growth factor binding protein 2 (IGFBP2). The upregulation of these cytokines in the $D^{\text {hi }}$ cells is what contributes to their therapeutic efficacy in supporting bone marrow regeneration in vivo.

Figure 4F quantifies the effect of PDMS substratum stiffness on osteopontin expression for the microfluidically isolated $D^{\text {hi }}$ and $D^{\text {lo }}$ subpopulations. For both unsorted and sorted subpopulations, OPN expression increased with decreasing PDMS substratum stiffness and always exceeded the expression levels obtainable for that group on tissue-culture-treated PS. Remarkably, OPN expression increased up to 5-fold for $D^{\text {hi }}$ cells on the most compliant PDMS ( $1 \mathrm{kPa}$ ) compared with unsorted cells on the standard culture substratum of tissueculture-treated PS. Furthermore, OPN expression of $D^{\text {lo }}$ cells cultured on compliant PDMS increased to similar levels as the $D^{\text {hi }}$ cells grown on tissue-culture-treated PS. In other words, we attained the same or greater levels of OPN production for smaller (non-osteoprogenitor) cells on compliant substratum material as for the larger (osteoprogenitor) cells under currently standard in vitro conditions. In addition to this inverse correlation between PDMS substratum stiffness and OPN expression, we also observed significant mechanical modulation of six other secreted proteins (IL-8, MCP-1, SDF1a, IL-21, BDNF, and bNGF) (Figure 5). Together, these data indicate that the mechanical characteristics of the PDMS substratum material-denoted succinctly but incompletely by the effective elastic moduli ranging 1 to $100 \mathrm{kPa}$ - can be varied to modulate production of secretome components in vitro that have been correlated with improved in vivo outcomes.

3.5. Mechanical Modulation of the MSC Secretome. In our study, osteopontin acts as a correlative marker for our $D^{\text {hi }}$ cell phenotype that is effective in hematopoietic recovery in vivo. However, we were also interested to learn what other secreted factors may also be coregulated by our PDMS substrata. Using a Luminex-based multiplex antibody array, we paneled over 45 different secreted proteins and cytokines. We collected the secretome samples (i.e., hMSC-conditioned media) from cells grown on our PDMS substrata and on polystyrene. We found that there were 13 factors that exhibited significant trends or large changes in expression ( $>2$-fold change) across our substrata (Figure 5). Of these 13 factors, six of them (IL-8, MCP-1, SDF-1a, IL-21, BDNF, and bNGF) exhibited significant rank-based correlations with PDMS stiffness when considering only PDMS substrata and excluding the polystyrene condition (Figure 5). These data suggest that we can mechanically modulate more than one factor or cytokine of the MSC secretome.

3.6. Coculture with HSPCs. To determine whether such a mechanically modulated secretome was sufficient to affect biologically relevant outcomes, we then cocultured human HSPCs - a cell type that grows in suspension-with human MSCs adhered to PDMS of varied stiffness. These MSCs were unsorted and thus corresponded to the control conditions reflected in Figure 4 and all conditions in Figure 5. As a standard of comparison, we also considered a typical HSPC expansion protocol with no MSCs present in PS wells. Indeed, Figure 6A shows that HSPC proliferation depended strongly on the substratum material to which the MSCs were adhered and was maximized for the most compliant PDMS substratum (1 $\mathrm{kPa}$ ). In separate experiments that quantified HSPC proliferation under contact coculture with the MSCs that were adhered to the substrata, we observed similar increases in proliferation with decreasing PDMS stiffness (see Figure S10). Percentages of HSPCs expressing surface antigens indicating common myeloid and lymphoid progenitor commitment (CD123+ and CD10+, respectively) were not modulated by MSC substratum 
A

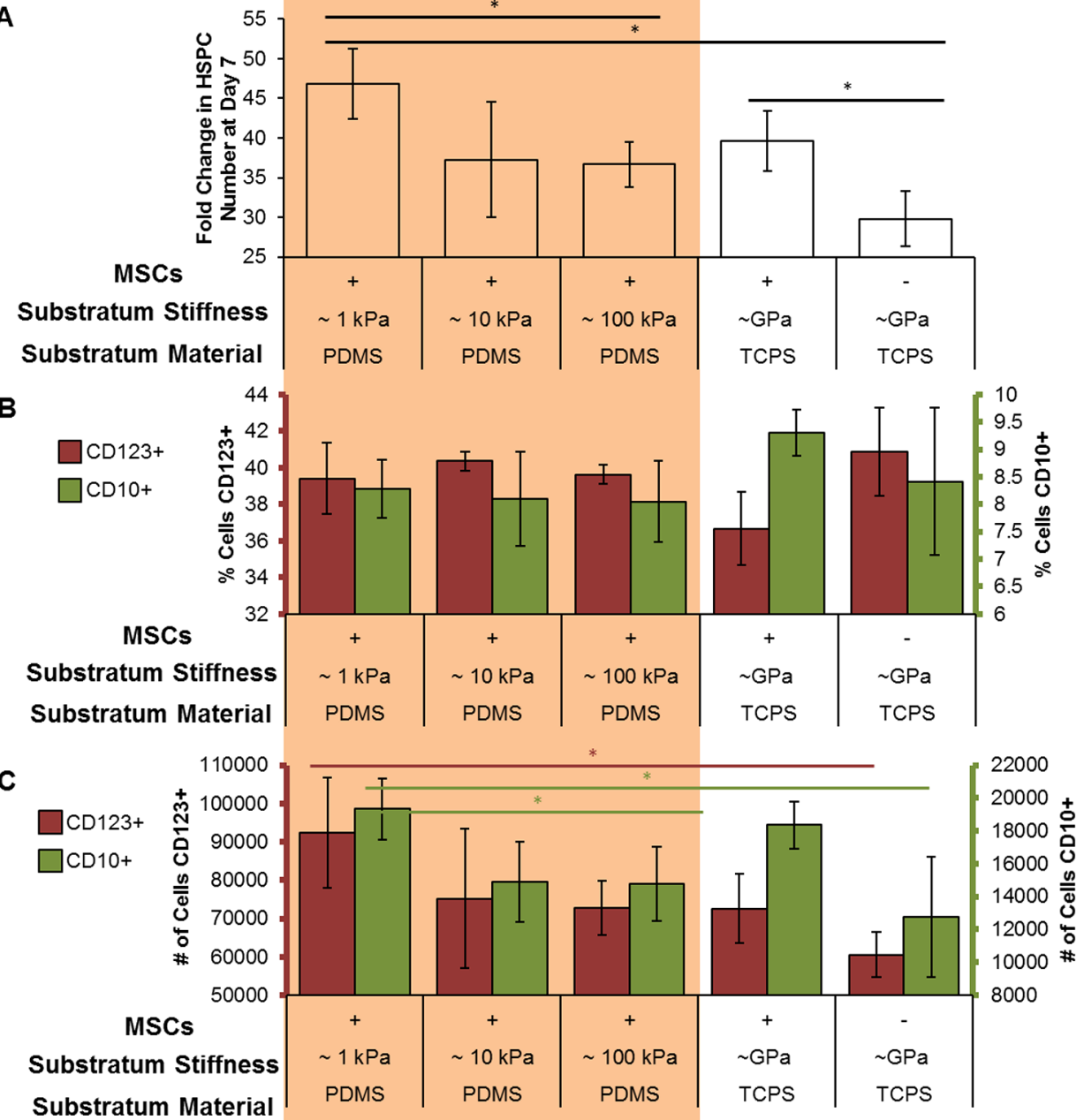

Figure 6. Effects of the mechanically modulated MSC secretome on hematopoietic stem and progenitor cells. (A) HSPCs were counted 7 days after being in noncontact coculture with MSCs on various substrata. Far right bars represent typical HSPC growth conditions with no hMSCs on tissueculture-treated polystyrene. Conditions where cells were grown on PDMS substrata are highlighted in orange. (B, C) Surface marker expression of CD123 (maroon) and CD10 (dark green) were assayed using flow cytometry: (B) percentage of positive CD123 expression is displayed on the left, primary axis, and the percentage of positive CD10 expression on the right, secondary axis; (C) number of positive CD123-expressing cells is displayed on the left, primary axis, and the number of positive CD10-expressing cells on the right, secondary axis. Statistical differences were determined using the unpaired one-tailed Student's $t$ test with unequal variance $(*, p<0.05)$.

stiffness (Figure 6B). In contrast, we observed that HSPC expression of CD34+ increased and CD123+ decreased with decreasing PDMS stiffness when in contact coculture with MSCs (see Figure S10). Thus, the absolute numbers of HSPCs expressing either CD123+ or CD10+ (Figure 6C) were both maximized in coculture for the most compliant MSC substrata. After coculture and upon chemical induction of these HSPCs into terminal erythrocyte lineages, cells appeared red, enucleated, and expressed CD235A (see Figure S11 and the associated discussion). This finding is consistent with retention of the ability to terminally differentiate into red blood cells.

\section{DISCUSSION}

Several previous studies have considered how mechanically compliant or deformable microenvironments can influence the terminal differentiation of MSCs along tissue cell lineages. In contrast, here we show that changes in expression of important cytokines such as osteopontin can be modulated significantly by varying the mechanical properties of cell culture substrata materials prior to detectable differences in terminal differentiation indicators such as osteogenic mineral deposition. It remains debated how deformable cell culture environments comprising different material types (e.g., hydrogels vs silicone elastomers) may influence terminal differentiation. ${ }^{9,64-66}$ On hydrogel-based materials, MSCs express more osteogenic markers when grown on substrata in the $\sim 25-40 \mathrm{kPa}$ range compared with substrata of lower stiffness. ${ }^{9,64,66}$ On PDMS substrata, previous studies have demonstrated an apparent insensitivity of human MSCs to substratum stiffness over the nominal elastic modulus range from $0.1 \mathrm{kPa}$ to $2.3 \mathrm{MPa}$, as expressed in terms of chemically induced terminal differentiation assessed by alkaline phosphatase assay. ${ }^{64,66}$ Here we confirmed those findings via a distinct assay for terminal osteogenic induction (Alizarin Red staining): no detectable changes in MSC mineral deposition associated with terminal osteogenic differentiation were observed for a stiffness range spanning 3 orders of magnitude ( 1 to $100 \mathrm{kPa}$ ).

It should be noted that we varied the mechanical properties using this silicone-based elastomer because it is nonporous (relative to typical hydrogels) and is not anticipated to promote differential tethering of extracellular matrix proteins to the material surface. ${ }^{66}$ Typical techniques of covalently binding 
matrix ligands such as collagen to the PDMS surface have been unfruitful. In fact, collagen may self-cross-link rather than bind covalently to the material surface. ${ }^{64}$ Indeed, we found that functionalization of PDMS with collagen I abrogated the pronounced changes in cytokine expression with substratum stiffness (see Figure S8). This suggests that for current state-ofthe-art collagen functionalization methods on PDMS, MSC cytokine expression is either dominated by the biochemical cue presented by this matrix ligand or that the effectively self-crosslinked collagen layer atop the differentially cross-linked PDMS presents a uniform mechanical environment to adherent cells. Thus, in our studies reported in Figures $1-6$ we employed nonspecific serum protein adsorption to oxygen-plasma-treated PDMS (previously termed tissue culture $\mathrm{PDMS}^{70}$ ). We identified no differences in the extent of ligand attachment, as confirmed in Figure 1 via surface hydrophobicity and protein adsorption comparisons. We also explored whether the adsorbed serum protein composition differed detectably across the PDMS substrata and observed no differences in band patterns on a 1D SDS-PAGE gel (Figure S3). These three points of comparison together support the claim that the total amount and types of serum proteins adsorbed to these substrata were indistinguishable, though these metrics do not rule out the possibility that the conformation of some protein(s) could differ among the three substrata types. Thus, the observed changes in cell behavior correlated more directly with the viscoelastic properties of these substrata materials than with the specific surface biochemical properties of these materials.

Others have posited that PDMS formulations are simply too stiff to elicit a mechanosensitive response by MSCs. ${ }^{64,73}$ This suggestion is due in part to prior studies that reported similar results for cells on the stiffest hydrogels considered (tens of $\mathrm{kPa}$ ) and cells on much stiffer glass $(10 \mathrm{~s} \mathrm{GPa})$ and to reports that tissue environments in the mesenchymal lineage are less stiff than many PDMS compositions. ${ }^{9,64}$ However, here we have shown that sparse cultures of MSCs (i.e., fewer cells per unit area than used for our studies of mechanosensitive expression) can mechanically deform PDMS ranging in nominal elastic modulus from 1 to $100 \mathrm{kPa}$ and that the extent of visible deformations (e.g., surface wrinkling) increases with decreasing viscoelastic moduli of the bulk polymer (Figures 1A-C and 2A,B; see Figures S4 and S5 for further discussion of this cell-contractility-induced surface wrinkling).

We also observed that mean cell diameter $\bar{D}$ increased with increasing substratum stiffness upon population doubling (Figure 2C, day 5). Although this general finding is in agreement with prior studies indicating that cells are more spread or appear larger on stiffer materials, ${ }^{9,65}$ here these changes were slight, with only a $\sim 0.5 \mu$ m difference in mean cell diameter for an order of magnitude difference in nominal substratum stiffness (Figure 2C). We observed much greater differences in cell diameter between biophysically sorted MSC groups, with the mean cell diameter differing by $\sim 5 \mu \mathrm{m}$ between the sorted subsets of $D^{\text {hi }}$ and $D^{\text {lo }}$ cell subpopulations (Figure 4A). Thus, the PDMS stiffness did not alter the MSC biophysical phenotype or differentiation potential significantly (Figure 3E,F) but did correlate with changes in secretome components such as osteopontin (Figure 3A-D and Figure 5). These substratum-stiffness-correlated changes in cell size were not apparent upon initial adhesion and spreading, indicating that cells responded to the mechanical cue over time and did not selectively adhere to materials of varying stiffness in a manner correlated with initial cell size. Together, the capacities of these cells to deform the substrata and exhibit population shifts in cell size indicate that these cells, considered as putative MSCs, can actively sense and respond to mechanical cues presented by these PDMS substrata.

We characterized these PDMS materials via macroscale shear rheology because they are viscoelastic materials that are dominated by the viscous component (loss modulus $G^{\prime \prime}$ ) as the stiffness (storage modulus) decreases. As a result, the shear storage or elastic moduli (expressed as $G^{\prime}$ ) varied significantly with strain rate, and thus, the substratum material may plausibly also vary in effective stiffness as cells exert force against it at varying rates. Methods that infer mechanical stiffness, e.g., by simplifying the material description to a linear elastic solid described by a single elastic modulus, can fail to identify accurately or completely the mechanical differences that may affect adherent cell responses (see the SI and Figure S2AC). ${ }^{53,63,74}$ Fuller descriptors of nonlinear elastic behavior of polymers utilized as cell culture substrata can be helpful in identifying such possibilities. For example, Chaudhuri and coworkers showed that MSCs exhibited increased cell spread area and expression of some osteogenic markers when cultured on polymers of shorter versus longer stress relaxation time constants. In that set of polymers, the viscous component of substratum deformation exhibited larger differences than the elastic components described by $G^{\prime}$ at a specific frequency, and thus, the authors attributed the differential cell response to time-dependent deformation of the substrata. ${ }^{53,63}$ While our present study utilized polymers for which $G^{\prime}$ and $G^{\prime \prime}$ were coupled and thus could not distinguish the independent roles of elastic and viscous contributions to MSC secretome modulation, Figure 3D clearly shows that OPN expression correlated with the ratio of these viscoelastic descriptors, $\tan (\delta)$. It thus remains an interesting vein of future studies to determine whether and how viscous characteristics of the cell culture substrata, independently of elastic properties of the material, can play a dominant role in modulating these MSC secretome expression levels. For both brevity and relation to prior studies, here we refer to these distinctly viscoelastic materials in terms of stiffness, ranging in nominal elastic moduli from 1 to $100 \mathrm{kPa}$ at a shear frequency of $1 \mathrm{~Hz}$.

Although within 1 week of chemical induction these mechanical cues were insufficient to elicit stiffness-dependent changes in the extent of terminal differentiation, the viscoelastic properties of PDMS correlated with significant changes in osteopontin expression (Figures 3A-D). Others have argued that culturing MSCs on PDMS of varying stiffness does not elicit measurable changes in MSC spreading or differentiation. $^{64,66}$ Similar to these previous studies, we did not observe changes in terminal differentiation potential (Figure 3E,F), but we did note significant changes in MSC size (Figure 2C). More importantly, PDMS stiffness is correlated with modulation of the secretory profile through which the MSCs support indirect repair in vivo (Figure 5). Most notably, osteopontin production was further increased on more compliant substrata for a size-sorted subset of putative osteochondral progenitor MSCs that were already upregulated in osteopontin (Figure 4F). Osteopontin was originally named and identified as an extracellular matrix protein that is important for calcium binding, biomineralization, osteoclast anchoring, and bone formation. ${ }^{75,76}$ Thus, it serves as an important marker for osteogenic commitment in MSCs. ${ }^{14}$ As osteopontin is a marker of osteogenic commitment, one might 
expect osteopontin expression to increase with increasing substratum stiffness, in keeping with prior reports that stiffer materials promote osteogenic commitment of MSCs. ${ }^{9,65}$ However, we observed uniformly lower osteopontin expression for MSCs adhered to stiffer PDMS substrata, whether for the control heterogeneous population of putative MSCs or for biophysically sorted subsets. (At the mRNA level (Figure 3A), we observed a monotonic correlation of decreased osteopontin transcription with increased substratum stiffness. At the secreted protein level (Figure 3B), this correlation was not monotonic; secreted osteopontin levels were lowest for cells on PDMS of $100 \mathrm{kPa}$ stiffness but similar for cells on PDMS of intermediate and lowest stiffness. This discrepancy may be attributed to differences in processes such as protein translation, degradation, and adsorption.) Moreover, this contradiction to expectation can be understood by noting that osteopontin is not only or chiefly a lineage commitment marker, despite its name. ${ }^{77,78}$ This cytokine serves a complex role as a paracrine signal and can be found in several different isoforms and splice variants with many post-translational modifications of serine residues as phosphorylation sites. Osteopontin plays an important role in both secreted and intracellular forms, ${ }^{79}$ for example by promoting angiogenesis via direct interaction with endothelial cells. ${ }^{80}$ This glycoprotein also contains an integrin-binding RGD sequence and a cryptic binding site exposed by thrombin cleavage, and it is a known ligand for another glycoprotein, CD44, a receptor that is expressed on T-cells. This interaction with CD44 has been shown to regulate IL-12, IL-10, and interferon- $\gamma$ production from macrophages in cell-mediated immunity. ${ }^{81}$ More importantly, the expression of osteopontin has been linked directly with hematopoietic niche maintenance after damage or from aging in vivo. ${ }^{82-84}$ Osteopontin has also been shown to regulate the location, differentiation and proliferation of HSPCs in vivo. ${ }^{85-87}$

The mechanically correlated osteopontin expression that we observed was conserved across multiple MSC donor sources tested (Figure S7), among subpopulations sorted from a single donor (Figure 4), and also for many other cytokines and growth factors that contribute to hematopoietic recovery (Figure 5). This robust response suggests an efficient means by which to mechanically prime the entire MSC population toward the $D^{\text {hi }}$ cell phenotype that supports bone marrow repair. By engineering the substratum stiffness, with or without biophysical sorting of MSC subpopulations that adhere to that material, we can induce the cell population to produce more of these beneficial factors. This mechanical priming can be useful whether the cells or those secreted proteins are the administered therapeutic product. For example, the $D^{\text {hi }}$ cells promote bone marrow repair and regeneration in lethally irradiated mice through their secretome but are limited in number. $^{20,41}$ Thus, we need to engineer either increased expression of the effective secretome components or more of the MSCs similar to the $D^{\text {hi }}$ cell phenotype. Here we have demonstrated that osteopontin expression is increased up to 5fold with respect to current in vitro culture materials when these $D^{\text {hi }}$ cells are biophysically sorted and cultured on compliant PDMS substrata of nominal $1 \mathrm{kPa}$ stiffness. As importantly, we showed that $D^{\text {lo }}$ cells (the dominant subpopulation, representing $\sim 80 \%$ of the heterogeneous MSCs, of otherwise reduced therapeutic outcome) cultured on compliant PDMS substrata exhibit increased osteopontin expression to approach levels produced by those $D^{\text {hi }}$ cells on polystyrene (Figure $4 \mathrm{~F}$ ). This finding shows that substratum materials can be designed to engineer a larger quantity of MSC-derived cells with the desired phenotype either by uniformly upregulating cytokine production by the heterogeneous MSC population or by selectively increasing cytokine production in the dominant subpopulation.

In physically sorted cells, MSC production of osteopontin was coregulated with other factors such as IGFBP2 and IL-8 (Figure 4E), both of which promote hematopoietic growth and immune regulation. ${ }^{88-90}$ This coregulation of other factors along with osteopontin was consistent in the unsorted population of MSCs grown on PDMS. Six other cytokines or growth factors (IL-8, MCP-1, SDF-1a, IL-21, BDNF, and bNGF; Figure 5) exhibited significant trends at the protein level similar to osteopontin. That is, all of these secreted factors exhibited increasing protein expression with decreasing substratum stiffness. One or more of these factors could contribute to the improved in vitro expansion of HSPCs (Figure 6). For example, IL-8 has been shown to support mobilization of HSPCs and the long-term repopulating ability of HSPCs in vivo. ${ }^{90}$ Increased IL-8 expression in early-passage MSCs was shown to be key in supporting in vitro expansion of HSPCs. ${ }^{91}$ Another mechanically modulated factor, SDF-1a, is a bone marrow niche component necessary to maintain a primitive state of the HSPCs in long-term ex-vivo culture. ${ }^{92-94}$ Although it may not directly affect HSPC expansion in vitro, MCP-1 (also known as CCR2) has been shown to promote trafficking of HSPCs to sites of inflammation in vivo. ${ }^{95,96} \mathrm{IL}-21$ can regulate downstream differentiation of HSPCs, such as accelerating NK cell maturation or inducing $\mathrm{B}$ cell maturation and apopotosis. $^{97,98}$ While IL-21 and MCP-1 may not be expected to improve ex vivo expansion of HSPCs directly, they may regulate hematopoiesis and inflammatory processes in vivo. Together, these cytokines and growth factors expressed by MSCs could play a role in influencing hematopoiesis both in vitro and in vivo.

The factors BDNF and bNGF are not known or thought to impact hematopoiesis, but upregulation of those factors could be useful for other applications. BDNF and bNGF promote growth and survival of neurons. ${ }^{99,100}$ These results suggest other potential in vitro applications or indirect repair targets for such mechanically modulated MSCs.

Such mechanical priming of the MSC secretome in vitro could plausibly support HSPC production in vitro and hematopoietic recovery in bone marrow upon in vivo administration. Figure 6 summarizes the effect of PDMS substratum stiffness on cocultured HSPCs. Here cells were cocultured under conditions preventing contact between the MSCs and HSPCs to explore the effects of the secretome independently of heterotypic cell-cell interactions and to decouple HSPC-substrata interactions ${ }^{101}$ (see the SI for a discussion of contact coculture conditions). MSCs ${ }^{82,83}$ and extracellular vesicles from $\mathrm{MSCs}^{102}$ have been shown to promote in vitro proliferation of HSPCs in coculture and prime the HSPCs for myeloid and erythroid commitment. In agreement with prior studies, we have demonstrated that the presence of MSCs (+MSC condition) can significantly increase HSPC proliferation compared with typical HSPC expansion conditions on PS in monoculture (-MSC condition) (Figure 6). ${ }^{89,94,103-105}$ Moreover, we found that HSPC proliferation increased even further over current materials and protocols when HSPCs were cocultured with MSCs adhered to PDMS substrata. This increase in HSPC proliferation with decreasing PDMS stiffness persisted for HSPCs in direct contact with the MSCs (see Figure S10), indicating that MSC secretome- 
stimulated proliferation is not abrogated by heterotypic cellcell contact. When expressed as a percentage increase in the fold change of HSPC proliferation, this capacity to produce HSPCs increased by $57 \%$ and $23 \%$ on PDMS of lowest $(1 \mathrm{kPa})$ and highest $(100 \mathrm{kPa})$ stiffness, respectively, with respect to HSPCs expanded on PS in the absence of MSCs (Figure 6A).

To explore whether lineage commitment of the HSPCs was also modulated by the MSC mechanical secretome, we compared HSPC expression of CD123+ (also known as IL-3 receptor) as a marker of common myeloid progenitor commitment $^{106,107}$ and $\mathrm{CD} 10+$ as a marker of common lymphoid progenitor commitment. ${ }^{108}$ For all conditions, the percentages of lymphoid and myeloid progenitor commitment were statistically indistinguishable compared to HSPCs expanded alone in monoculture on polystyrene (Figure 6B). This suggests that noncontact coculture with the mechanically modulated MSCs does not shift the differentiation potential of the HSPCs detectably. However, a significantly larger number of both CD123+- and CD10+-expressing HSPC subpopulations was obtained for noncontact coculture with MSCs adhered to the most compliant PDMS (Figure 6C). Proliferation of all progenitor phenotypes can thus be enhanced in vitro without altering the potential for subsequent terminal differentiation induction (Figure S11). One can maximize proliferative capacity of HSPCs while maintaining the differentiation potential across all lineages. As discussed in the SI, contact coculture promoted PDMS-stiffness-dependent expression of a myeloid progenitor marker (CD123+), so HSPC naïveté was not maintained upon direct contact with MSCs adhered to PDMS of varying stiffness (Figure S10). Future work will explore which known or other components of HSPC-MSC interactions and paracrine signaling facilitate this crosstalk. Modulation of the MSC mechanical environment via the adherent substratum is sufficient to then modulate proliferation and differentiation of a nonadherent stem cell class, HSPCs.

\section{CONCLUSIONS}

We have developed and demonstrated a facile, mechanically tunable PDMS system that supports MSC proliferation and progenitor cell production. This material design serves as an adherent cell substratum that can induce expression changes in important cytokines and growth factors of the MSC secretome, even prior to terminal differentiation. To illustrate this material mechanics approach, we increased by 5 -fold the production of one important MSC-secreted cytokine, osteopontin, through modulation of both the stiffness of PDMS substrata and the subpopulation of MSC-derived cells. Substratum stiffness also correlated with MSC production of six other secreted proteins, demonstrating a mechanically modulated MSC secretome that can now be explored further. Moreover, we have shown that systematic changes in cell substratum mechanics can shift the entire cell population toward a subpopulation phenotype (defined in part by these secreted factors) of established in vivo efficacy but low prevalence on current substratum materials. For MSC therapy applications such as bone marrow recovery, this materials-mediated approach increases the available cell number 5- to 6-fold by shifting the population toward this expression profile within 1 week in vitro. These mechanically tunable cell culture substrata provide a simple and effective alternative to modulate the MSC secretome compared with biochemical induction and genetic modification. This approach is also more readily amenable to scaled manufacturing of cell therapies, in contrast to viral transfection or chemical induction.

This MSC mechanopriming can be used to improve production of other cell types in vitro that can be subsequently used for in vivo applications such as hematopoietic recovery. For example, here HSPC proliferation was maximized in noncontact coculture with MSCs adhered to the most compliant PDMS without altering the multipotency of HSPCs for either myeloid (blood cell) or lymphoid (immune cell) lineages. Such increased production efficiency of HSPCderived progenitors suggests promising clinical implications in simultaneously maximizing proliferation and differentiation of multiple hematopoietic lineages in vitro.

\section{ASSOCIATED CONTENT}

\section{S Supporting Information}

The Supporting Information is available free of charge on the ACS Publications website at DOI: 10.1021/acsbiomaterials. 7 b00644.

Further discussion of MSC secretome and viscoelastic characterization of PDMS material (Figures S1 and S2), PDMS surface characterization of adsorbed protein (Figure S3), wrinkling (Figures S4 and S5), cell size distributions and histograms (Figure S6), biological replicates (Figure S7), surface functionalization (Figure S8), chondrogenic gene expression (Figure S9), contact coculture with HSPCs (Figure S10), and differentiation of HSPCs (Figure S11) (PDF)

\section{AUTHOR INFORMATION}

\section{Corresponding Author}

*E-mail: krystyn@mit.edu. Telephone: (617) 253-3315. ORCID $\odot$

Krystyn J. Van Vliet: 0000-0001-5735-0560

\section{Author Contributions}

F.D.L. designed and executed the experiments, analyzed the data, and wrote the paper. N.P. designed and executed the HSPC experiments with F.D.L. and edited those components of the paper. T.K. and Z.P. contributed to study design and discussion, and T.K. contributed Luminex-based data. K.J.V.V. designed the study, interpreted the data, and wrote the paper. All of the authors reviewed the manuscript, figures, and supporting information.

\section{Notes}

The authors declare no competing financial interest.

\section{ACKNOWLEDGMENTS}

We gratefully acknowledge support from the BioSystems \& Micromechanics (BioSyM) Singapore-MIT Alliance for Research and Technology through the Singapore National Research Foundation (F.D.L. and K.J.V.V.) and from the U.S. National Institutes of Health (Grant 2 P01 HL032262-25 to H.F.L.). This work made use of the Shared Experimental Facilities supported in part by the MRSEC Program of the U.S. National Science Foundation under Award DMR-1419807. We thank H. F. Lodish (H.F.L.) for helpful discussions and H. L. Ploegh for Whitehead Institute laboratory equipment access.

\section{REFERENCES}

(1) Caplan, A. I. Mesenchymal Stem Cells. J. Orthop. Res. 1991, 9 (5), 641-650. 
(2) Pittenger, M. F.; Mackay, A. M.; Beck, S. C.; Jaiswal, R. K.; Douglas, R.; Mosca, J. D.; Moorman, M. A.; Simonetti, D. W.; Craig, S.; Marshak, D. R. Multilineage Potential of Adult Human Mesenchymal Stem Cells. Science 1999, 284 (5411), 143-147.

(3) Tuan, R. S.; Boland, G.; Tuli, R. Adult Mesenchymal Stem Cells and Cell-Based Tissue Engineering. Arthritis Res. Ther. 2003, 5 (1), $32-45$

(4) Caplan, A. I. Adult Mesenchymal Stem Cells for Tissue Engineering versus Regenerative Medicine. J. Cell. Physiol. 2007, 213 (2), 341-347.

(5) Chapel, A.; Bertho, J. M.; Bensidhoum, M.; Fouillard, L.; Young, R. G.; Frick, J.; Demarquay, C.; Cuvelier, F.; Mathieu, E.; Trompier, F.; Dudoignon, N.; Germain, C.; Mazurier, C.; Aigueperse, J.; Borneman, J.; Gorin, N. C.; Gourmelon, P.; Thierry, D. Mesenchymal Stem Cells Home to Injured Tissues When Co-Infused with Hematopoietic Cells to Treat a Radiation-Induced Multi-Organ Failure Syndrome. J. Gene Med. 2003, 5 (12), 1028-1038.

(6) Karp, J. M.; Leng Teo, G. S. Mesenchymal Stem Cell Homing: The Devil Is in the Details. Cell Stem Cell 2009, 4 (3), 206-216.

(7) Khaldoyanidi, S. Directing Stem Cell Homing. Cell Stem Cell 2008, 2 (3), 198-200.

(8) Wei, X.; Yang, X.; Han, Z.; Qu, F.; Shao, L.; Shi, Y. Mesenchymal Stem Cells: A New Trend for Cell Therapy. Acta Pharmacol. Sin. 2013, 34 (6), 747-754

(9) Engler, A. J.; Sen, S.; Sweeney, H. L.; Discher, D. E. Matrix Elasticity Directs Stem Cell Lineage Specification. Cell 2006, 126 (4), 677-689.

(10) Guilak, F.; Cohen, D. M.; Estes, B. T.; Gimble, J. M.; Liedtke, W.; Chen, C. S. Control of Stem Cell Fate by Physical Interactions with the Extracellular Matrix. Cell Stem Cell 2009, 5 (1), 17-26.

(11) Chen, C. S.; Mrksich, M.; Huang, S.; Whitesides, G. M.; Ingber, D. E. Micropatterned Surfaces for Control of Cell Shape, Position, and Function. Biotechnol. Prog. 1998, 14 (3), 356-363.

(12) Lee, J.; Abdeen, A. a; Zhang, D.; Kilian, K. a. Directing Stem Cell Fate on Hydrogel Substrates by Controlling Cell Geometry, Matrix Mechanics and Adhesion Ligand Composition. Biomaterials 2013, 34 (33), 8140-8148.

(13) Mcbeath, R.; Pirone, D. M.; Nelson, C. M.; Bhadriraju, K.; Chen, C. S. Cell Shape, Cytoskeletal Tension, and RhoA Regulate Stem Cell Lineage Commitment. Dev. Cell 2004, 6, 483-495.

(14) Dalby, M. J.; Gadegaard, N.; Oreffo, R. O. C. Harnessing Nanotopography and Integrin-Matrix Interactions to Influence Stem Cell Fate. Nat. Mater. 2014, 13 (6), 558-569.

(15) van Velthoven, C. T. J.; Kavelaars, A.; van Bel, F.; Heijnen, C. J. Mesenchymal Stem Cell Treatment after Neonatal Hypoxic-Ischemic Brain Injury Improves Behavioral Outcome and Induces Neuronal and Oligodendrocyte Regeneration. Brain, Behav., Immun. 2010, 24 (3), 387-393.

(16) Chen, J.; Li, Y.; Wang, L.; Zhang, Z.; Lu, D.; Lu, M.; Chopp, M. Therapeutic Benefit of Intravenous Administration of Bone Marrow Stromal Cells After Cerebral Ischemia in Rats. Stroke 2001, 32 (4), $1005-1011$.

(17) Chen, S.; Fang, W.; Ye, F.; Liu, Y.-H.; Qian, J.; Shan, S.; Zhang, J.; Chunhua, R. Z.; Liao, L.; Lin, S.; Sun, J. Effect on Left Ventricular Function of Intracoronary Transplantation of Autologous Bone Marrow Mesenchymal Stem Cell in Patients with Acute Myocardial Infarction. Am. J. Cardiol. 2004, 94 (1), 92-95.

(18) Miyahara, Y.; Nagaya, N.; Kataoka, M.; Yanagawa, B.; Tanaka, K.; Hao, H.; Ishino, K.; Ishida, H.; Shimizu, T.; Kangawa, K.; Sano, S.; Okano, T.; Kitamura, S.; Mori, H. Monolayered Mesenchymal Stem Cells Repair Scarred Myocardium after Myocardial Infarction. Nat. Med. 2006, 12 (4), 459-465.

(19) Cheng, Z.; Ou, L.; Zhou, X.; Li, F.; Jia, X.; Zhang, Y.; Liu, X.; Li, Y.; Ward, C. a; Melo, L. G.; Kong, D. Targeted Migration of Mesenchymal Stem Cells Modified with CXCR4 Gene to Infarcted Myocardium Improves Cardiac Performance. Mol. Ther. 2008, 16 (3), 571-579.

(20) Poon, Z.; Lee, W. C.; Guan, G.; Nyan, L. M.; Lim, C. T.; Han, J.; Van Vliet, K. J. Bone Marrow Regeneration Promoted by
Biophysically Sorted Osteoprogenitors from Mesenchymal Stromal Cells. Stem Cells Transl. Med. 2015, 4 (1), 56-65.

(21) Lin, P.; Correa, D.; Kean, T. J.; Awadallah, A.; Dennis, J. E.; Caplan, A. I. Serial Transplantation and Long-Term Engraftment of Intra-Arterially Delivered Clonally Derived Mesenchymal Stem Cells to Injured Bone Marrow. Mol. Ther. 2014, 22 (1), 160-168.

(22) Ankrum, J.; Karp, J. M. Mesenchymal Stem Cell Therapy: Two Steps Forward, One Step Back. Trends Mol. Med. 2010, 16 (5), 203209.

(23) Lee, R. H.; Pulin, A. A.; Seo, M. J.; Kota, D. J.; Ylostalo, J.; Larson, B. L.; Semprun-prieto, L.; Delafontaine, P.; Prockop, D. J. Intravenous hMSCs Improve Myocardial Infarction in Mice Because Cells Embolized in Lung Are Activated to Secrete the AntiInflammatory Protein TSG-6. Cell Stem Cell 2009, 5 (1), 54-63.

(24) Zimmerlin, L.; Park, T. S.; Zambidis, E. T.; Donnenberg, V. S.; Donnenberg, A. D. Mesenchymal Stem Cell Secretome and Regenerative Therapy after Cancer. Biochimie 2013, 95 (12), 22352245

(25) Nauta, A. J.; Fibbe, W. E. Immunomodulatory Properties of Mesenchymal Stromal Cells. Blood 2007, 110 (10), 3499-3506.

(26) Akiyama, K.; Chen, C.; Wang, D.; Xu, X.; Qu, C.; Yamaza, T.; Cai, T.; Chen, W.; Sun, L.; Shi, S. Mesenchymal-Stem-Cell-Induced Immunoregulation Involves FAS-Ligand-/FAS-Mediated $\mathrm{T}$ Cell Apoptosis. Cell Stem Cell 2012, 10 (5), 544-555.

(27) Bai, L.; Lennon, D. P.; Eaton, V.; Maier, K.; Caplan, A. I.; Miller, S. D.; Miller, R. H. Human Bone Marrow-Derived Mesenchymal Stem Cells Induce Th2-Polarized Immune Response and Promote Endogenous Repair in Animal Models of Multiple Sclerosis. Glia 2009, 57 (11), 1192-1203.

(28) Ryan, J. M.; Barry, F.; Murphy, J. M.; Mahon, B. P. InterferonGamma Does Not Break, but Promotes the Immunosuppressive Capacity of Adult Human Mesenchymal Stem Cells. Clin. Exp. Immunol. 2007, 149 (2), 353-363.

(29) Le Blanc, K.; Ringdén, O. Mesenchymal Stem Cells: Properties and Role in Clinical Bone Marrow Transplantation. Curr. Opin. Immunol. 2006, 18 (5), 586-591.

(30) Abdeen, A. A.; Weiss, J. B.; Lee, J.; Kilian, K. A. Matrix Composition and Mechanics Direct Proangiogenic Signaling from Mesenchymal Stem Cells. Tissue Eng., Part A 2014, 20 (19-20), 27372745

(31) Prockop, D. J.; Oh, J. Y. Mesenchymal Stem/stromal Cells (MSCs): Role as Guardians of Inflammation. Mol. Ther. 2012, 20 (1), 14-20.

(32) Duffy, G. P.; Ahsan, T.; O’Brien, T.; Barry, F.; Nerem, R. M. Bone Marrow-Derived Mesenchymal Stem Cells Promote Angiogenic Processes in a Time- and Dose-Dependent Manner In Vitro. Tissue Eng., Part A 2009, 15 (9), 2459-2470.

(33) Uccelli, A.; Moretta, L.; Pistoia, V. Mesenchymal Stem Cells in Health and Disease. Nat. Rev. Immunol. 2008, 8 (9), 726-736.

(34) Ranganath, S. H.; Levy, O.; Inamdar, M. S.; Karp, J. M. Harnessing the Mesenchymal Stem Cell Secretome for the Treatment of Cardiovascular Disease. Cell Stem Cell 2012, 10 (3), 244-258.

(35) Paul, G.; Anisimov, S. V. The Secretome of Mesenchymal Stem Cells: Potential Implications for Neuroregeneration. Biochimie 2013, 95 (12), 2246-2256

(36) Parr, a M.; Tator, C. H.; Keating, a. Bone Marrow-Derived Mesenchymal Stromal Cells for the Repair of Central Nervous System Injury. Bone Marrow Transplant. 2007, 40 (7), 609-619.

(37) Aggarwal, S.; Pittenger, M. F. Human Mesenchymal Stem Cells Modulate Allogeneic Immune Cell Responses. Blood 2005, 105 (4), $1815-1822$

(38) Parekkadan, B.; van Poll, D.; Suganuma, K.; Carter, E. a; Berthiaume, F.; Tilles, A. W.; Yarmush, M. L. Mesenchymal Stem CellDerived Molecules Reverse Fulminant Hepatic Failure. PLoS One 2007, 2 (9), e941.

(39) van Poll, D.; Parekkadan, B.; Cho, C. H.; Berthiaume, F.; Nahmias, Y.; Tilles, A. W.; Yarmush, M. L. Mesenchymal Stem CellDerived Molecules Directly Modulate Hepatocellular Death and 
Regeneration in Vitro and in Vivo. Hepatology 2008, 47 (5), 16341643

(40) Drago, D.; Cossetti, C.; Iraci, N.; Gaude, E.; Musco, G.; Bachi, A.; Pluchino, S. The Stem Cell Secretome and Its Role in Brain Repair. Biochimie 2013, 95, 2271-2285.

(41) Lee, W. C.; Shi, H.; Poon, Z.; Nyan, L. M.; Kaushik, T.; Shivashankar, G. V.; Chan, J. K. Y.; Lim, C. T.; Han, J.; Van Vliet, K. J. Multivariate Biophysical Markers Predictive of Mesenchymal Stromal Cell Multipotency. Proc. Natl. Acad. Sci. U. S. A. 2014, 111 (42), E4409-E4418.

(42) Whitfield, M. J.; Lee, W. C. J.; Van Vliet, K. J. Onset of Heterogeneity in Culture-Expanded Bone Marrow Stromal Cells. Stem Cell Res. 2013, 11 (3), 1365-1377.

(43) Hoch, A. I.; Leach, J. K. Concise Review: Optimizing Expansion of Bone Marrow Mesenchymal Stem/stromal Cells for Clinical Applications. Stem Cells Transl. Med. 2014, 3 (5), 643-652.

(44) Dominici, M.; Le Blanc, K.; Mueller, I.; Slaper-Cortenbach, I.; Marini, F.; Krause, D.; Deans, R.; Keating, a; Prockop, D.; Horwitz, E. Minimal Criteria for Defining Multipotent Mesenchymal Stromal Cells. The International Society for Cellular Therapy Position Statement. Cytotherapy 2006, 8 (4), 315-317.

(45) Lee, W. C.; Bhagat, A. A. S.; Huang, S.; Van Vliet, K. J.; Han, J.; Lim, C. T. High-Throughput Cell Cycle Synchronization Using Inertial Forces in Spiral Microchannels. Lab Chip 2011, 11 (7), 13591367.

(46) Sacchetti, B.; Funari, A.; Michienzi, S.; Di Cesare, S.; Piersanti, S.; Saggio, I.; Tagliafico, E.; Ferrari, S.; Robey, P. G.; Riminucci, M.; Bianco, P. Self-Renewing Osteoprogenitors in Bone Marrow Sinusoids Can Organize a Hematopoietic Microenvironment. Cell 2007, 131 (2), 324-336.

(47) Bianco, P. Bone and the Hematopoietic Niche. Blood 2011, 117 (20), 5281-5289.

(48) Calvi, L. M.; Adams, G. B.; Weibrecht, K. W.; Weber, J. M.; Olson, D. P.; Knight, M. C.; Martin, R. P.; Schipani, E.; Divieti, P.; Bringhurst, F. R.; Milner, L. A.; Kronenberg, H. M.; Scadden, D. T. Osteoblastic Cells Regulate the Haematopoietic Stem Cell Niche. Nature 2003, 425 (6960), 841-846.

(49) Taichman, R. S.; Emerson, S. G. The Role of Osteoblasts in the Hematopoietic Microenvironment. Stem Cells 1998, 16 (1), 7-15.

(50) Yim, E. K. F.; Darling, E. M.; Kulangara, K.; Guilak, F.; Leong, K. W. Nanotopography-Induced Changes in Focal Adhesions, Cytoskeletal Organization, and Mechanical Properties of Human Mesenchymal Stem Cells. Biomaterials 2010, 31 (6), 1299-1306.

(51) Baker, B. A.; Pine, P. S.; Chatterjee, K.; Kumar, G.; Lin, N. J.; Mcdaniel, J. H.; Salit, M. L.; Simon, C. G. Ontology Analysis of Global Gene Expression Differences of Human Bone Marrow Stromal Cells Cultured on 3D Scaffolds or 2D Films. Biomaterials 2014, 35 (25), 6716-6726.

(52) Lutolf, M. P.; Gilbert, P. M.; Blau, H. M. Designing Materials to Direct Stem-Cell Fate. Nature 2009, 462 (7272), 433-441.

(53) Chaudhuri, O.; Gu, L.; Klumpers, D.; Darnell, M.; Bencherif, S. A.; Weaver, J. C.; Huebsch, N.; Lee, H.-P.; Lippens, E.; Duda, G. N.; Mooney, D. J. Hydrogels with Tunable Stress Relaxation Regulate Stem Cell Fate and Activity. Nat. Mater. 2016, 15 (3), 326-334.

(54) Schwartz, M. a; DeSimone, D. W. Cell Adhesion Receptors in Mechanotransduction. Curr. Opin. Cell Biol. 2008, 20 (5), 551-556.

(55) Li, B.; Moshfegh, C.; Lin, Z.; Albuschies, J.; Vogel, V. Mesenchymal Stem Cells Exploit Extracellular Matrix as Mechanotransducer. Sci. Rep. 2013, 3, 2425.

(56) Iyer, K. V.; Pulford, S.; Mogilner, A.; Shivashankar, G. V. Mechanical Activation of Cells Induces Chromatin Remodeling Preceding MKL Nuclear Transport. Biophys. J. 2012, 103 (7), $1416-1428$

(57) Talwar, S.; Kumar, A.; Rao, M.; Menon, G. I.; Shivashankar, G. V. Correlated Spatio-Temporal Fluctuations in Chromatin Compaction States Characterize Stem Cells. Biophys. J. 2013, 104 (3), 553564.

(58) Tajik, A.; Zhang, Y.; Wei, F.; Sun, J.; Jia, Q.; Zhou, W.; Singh, R.; Khanna, N.; Belmont, A. S.; Wang, N. Transcription Upregulation via Force-Induced Direct Stretching of Chromatin. Nat. Mater. 2016, 15 (12), 1287-1296.

(59) Wang, N. Stem Cell Mechanics: Auxetic Nuclei. Nat. Mater. 2014, 13 (6), 540-542.

(60) Halder, G.; Dupont, S.; Piccolo, S. Transduction of Mechanical and Cytoskeletal Cues by YAP and TAZ. Nat. Rev. Mol. Cell Biol. 2012, 13 (9), 591-600.

(61) Dupont, S.; Morsut, L.; Aragona, M.; Enzo, E.; Giulitti, S.; Cordenonsi, M.; Zanconato, F.; Le Digabel, J.; Forcato, M.; Bicciato, S.; Elvassore, N.; Piccolo, S. Role of YAP/TAZ in Mechanotransduction. Nature 2011, 474 (7350), 179-183.

(62) Aragona, M.; Panciera, T.; Manfrin, A.; Giulitti, S.; Michielin, F.; Elvassore, N.; Dupont, S.; Piccolo, S. A Mechanical Checkpoint Controls Multicellular Growth through YAP/TAZ Regulation by Actin-Processing Factors. Cell 2013, 154 (5), 1047-1059.

(63) Chaudhuri, O.; Gu, L.; Darnell, M.; Klumpers, D.; Bencherif, S. a; Weaver, J. C.; Huebsch, N.; Mooney, D. J. Substrate Stress Relaxation Regulates Cell Spreading. Nat. Commun. 2015, 6, 6365.

(64) Wen, J. H.; Vincent, L. G.; Fuhrmann, A.; Choi, Y. S.; Hribar, K. C.; Taylor-weiner, H.; Chen, S.; Engler, A. J. Interplay of Matrix Stiffness and Protein Tethering in Stem Cell Differentiation. Nat. Mater. 2014, 13 (10), 979-987.

(65) Fu, J.; Wang, Y.; Yang, M. T.; Desai, R. A.; Yu, X.; Liu, Z.; Chen, C. S. Mechanical Regulation of Cell Function with Geometrically Modulated Elastomeric Substrates. Nat. Methods 2010, 7 (9), $733-$ 736.

(66) Trappmann, B.; Gautrot, J. E.; Connelly, J. T.; Strange, D. G. T.; Li, Y.; Oyen, M. L.; Cohen Stuart, M. A.; Boehm, H.; Li, B.; Vogel, V.; Spatz, J. P.; Watt, F. M.; Huck, W. T. S. Extracellular-Matrix Tethering Regulates Stem-Cell Fate. Nat. Mater. 2012, 11 (7), 642-649.

(67) Engler, A.; Bacakova, L.; Newman, C.; Hategan, A.; Griffin, M.; Discher, D. Substrate Compliance versus Ligand Density in Cell on Gel Responses. Biophys. J. 2004, 86 (1), 617-628.

(68) Walton, E. B.; Lee, S.; Van Vliet, K. J. Extending Bell's Model: How Force Transducer Stiffness Alters Measured Unbinding Forces and Kinetics of Molecular Complexes. Biophys. J. 2008, 94 (7), 26212630.

(69) Maloney, J. M.; Walton, E. B.; Bruce, C. M.; Van Vliet, K. J. Influence of Finite Thickness and Stiffness on Cellular AdhesionInduced Deformation of Compliant Substrata. Phys. Rev. E - Stat. Nonlinear, Soft Matter Phys. 2008, 78 (4), 1-15.

(70) Zeiger, A. S.; Liu, F. D.; Durham, J. T.; Jagielska, A.; Mahmoodian, R.; Van Vliet, K. J.; Herman, I. M. Static Mechanical Strain Induces Capillary Endothelial Cell Cycle Re-Entry and Sprouting. Phys. Biol. 2016, 13 (4), 046006.

(71) Eyckmans, J.; Chen, C. S. Stem Cell Differentiation: Sticky Mechanical Memory. Nat. Mater. 2014, 13 (6), 542-543.

(72) Zeiger, A. S.; Hinton, B.; Van Vliet, K. J. Why the Dish Makes a Difference: Quantitative Comparison of Polystyrene Culture Surfaces. Acta Biomater. 2013, 9 (7), 7354-7361.

(73) Bartalena, G.; Loosli, Y.; Zambelli, T.; Snedeker, J. G. Biomaterial Surface Modifications Can Dominate Cell-substrate Mechanics: The Impact of PDMS Plasma Treatment on a Quantitative Assay of Cell Stiffness. Soft Matter 2012, 8 (3), 673-681.

(74) Toyjanova, J.; Hannen, E.; Bar-Kochba, E.; Darling, E. M.; Henann, D. L.; Franck, C. 3D Viscoelastic Traction Force Microscopy. Soft Matter 2014, 10 (40), 8095-8106.

(75) Haylock, D. N.; Nilsson, S. K. Osteopontin: A Bridge between Bone and Blood. Br. J. Haematol. 2006, 134 (5), 467-474.

(76) Reinholt, F. P.; Hultenby, K.; Oldberg, A.; Heinegard, D. Osteopontin-a Possible Anchor of Osteoclasts to Bone. Proc. Natl. Acad. Sci. U. S. A. 1990, 87 (June), 4473-4475.

(77) Denhardt, D. T.; Guo, X. Osteopontin: A Protein with Diverse Functions. FASEB J. 1993, 7, 1475-1482.

(78) Sodek, J.; Ganss, B.; McKee, M. D. Osteopontin. Crit. Rev. Oral Biol. Med. 2000, 11 (3), 279-303.

(79) Wang, K. X.; Denhardt, D. T. Osteopontin: Role in Immune Regulation and Stress Responses. Cytokine Growth Factor Rev. 2008, 19 (5-6), 333-345. 
(80) Dai, J.; Peng, L.; Fan, K.; Wang, H.; Wei, R.; Ji, G.; Cai, J.; Lu, B.; Li, B.; Zhang, D.; Kang, Y.; Tan, M.; Qian, W.; Guo, Y. Osteopontin Induces Angiogenesis through Activation of PI3K/AKT and ERK1/2 in Endothelial Cells. Oncogene 2009, 28, 3412-3422.

(81) Ashkar, S.; Weber, G. F.; Panoutsakopoulou, V.; Sanchirico, M. E.; Jansson, M.; Zawaideh, S.; Rittling, S. R.; Denhardt, D. T.; Glimcher, M. J.; Cantor, H. Eta-1 (Osteopontin): An Early Component of Type-1 (Cell-Mediated) Immunity. Science 2000, 287 (5454), 860-864.

(82) Carrancio, S.; Blanco, B.; Romo, C.; Muntion, S.; LopezHolgado, N.; Blanco, J. F.; Briñon, J. G.; San Miguel, J. F.; SanchezGuijo, F. M.; del Cañizo, M. C. Bone Marrow Mesenchymal Stem Cells for Improving Hematopoietic Function: An In Vitro and In Vivo Model. Part 2: Effect on Bone Marrow Microenvironment. PLoS One 2011, 6 (10), e26241.

(83) Perucca, S.; Di Palma, A.; Piccaluga, P. P.; Gemelli, C.; Zoratti, E.; Bassi, G.; Giacopuzzi, E.; Lojacono, A.; Borsani, G.; Tagliafico, E.; Scupoli, M. T.; Bernardi, S.; Zanaglio, C.; Cattina, F.; Cancelli, V.; Malagola, M.; Krampera, M.; Marini, M.; Almici, C.; Ferrari, S.; Russo, D. Mesenchymal Stromal Cells (MSCs) Induce Ex Vivo Proliferation and Erythroid Commitment of Cord Blood Haematopoietic Stem Cells (CB-CD34+ Cells). PLoS One 2017, 12 (2), e0172430.

(84) Guidi, N.; Sacma, M.; Ständker, L.; Soller, K.; Marka, G.; Eiwen, K.; Weiss, J. M.; Kirchhoff, F.; Weil, T.; Cancelas, J. A.; Florian, M. C.; Geiger, H. Osteopontin Attenuates Aging-associated Phenotypes of Hematopoietic Stem Cells. EMBO J. 2017, 36 (7), 840-853.

(85) Nilsson, S. K.; Johnston, H. M.; Whitty, G. A.; Williams, B.; Webb, R. J.; Denhardt, D. T.; Bertoncello, I.; Bendall, L. J.; Simmons, P. J.; Haylock, D. N. Osteopontin, a Key Component of the Hematopoietic Stem Cell Niche and Regulator of Primitive Hematopoietic Progenitor Cells. Blood 2005, 106 (4), 1232-1239.

(86) Sumitomo, A.; Ishino, R.; Urahama, N.; Inoue, K.; Yonezawa, K.; Hasegawa, N.; Horie, O.; Matsuoka, H.; Kondo, T.; Roeder, R. G.; Ito, M. The Transcriptional Mediator Subunit MED1/TRAP220 in Stromal Cells Is Involved in Hematopoietic Stem/progenitor Cell Support through Osteopontin Expression. Mol. Cell. Biol. 2010, 30 (20), 4818-4827.

(87) Stier, S.; Ko, Y.; Forkert, R.; Lutz, C.; Neuhaus, T.; Grünewald, E.; Cheng, T.; Dombkowski, D.; Calvi, L. M.; Rittling, S. R.; Scadden, D. T. Osteopontin Is a Hematopoietic Stem Cell Niche Component That Negatively Regulates Stem Cell Pool Size. J. Exp. Med. 2005, 201 (11), 1781-1791.

(88) Huynh, H.; Zheng, J.; Umikawa, M.; Zhang, C.; Silvany, R.; Iizuka, S.; Holzenberger, M.; Zhang, W.; Zhang, C. C. IGF Binding Protein 2 Supports the Survival and Cycling of Hematopoietic Stem Cells. Blood 2011, 118 (12), 3236-3243.

(89) Khoury, M.; Drake, A.; Chen, Q.; Dong, D.; Leskov, I.; Fragoso, M. F.; Li, Y.; Iliopoulou, B. P.; Hwang, W.; Lodish, H. F.; Chen, J. Mesenchymal Stem Cells Secreting Angiopoietin-like-5 Support Efficient Expansion of Human Hematopoietic Stem Cells without Compromising Their Repopulating Potential. Stem Cells Dev. 2011, 20 (8), 1371-1381.

(90) Laterveer, L.; Lindley, I. J.; Hamilton, M. S.; Willemze, R.; Fibbe, W. E. Interleukin-8 Induces Rapid Mobilization of Hematopoietic Stem Cells with Radioprotective Capacity and Long-Term Myelolymphoid Repopulating Ability. Blood 1995, 85 (8), 2269-2275.

(91) Briquet, A.; Dubois, S.; Bekaert, S.; Dolhet, M.; Beguin, Y.; Gothot, A. Prolonged Ex Vivo Culture of Human Bone Marrow Mesenchymal Stem Cells Influences Their Supportive Activity toward NOD/SCID-Repopulating Cells and Committed Progenitor Cells of B Lymphoid and Myeloid Lineages. Haematologica 2010, 95 (1), 47-56.

(92) Van Overstraeten-Schlögel, N.; Beguin, Y.; Gothot, A. Role of Stromal-Derived Factor-1 in the Hematopoietic-Supporting Activity of Human Mesenchymal Stem Cells. Eur. J. Haematol. 2006, 76 (6), 488-493.

(93) Sharma, M. B.; Limaye, L. S.; Kale, V. P. Mimicking the Functional Hematopoietic Stem Cell Niche in Vitro: Recapitulation of Marrow Physiology by Hydrogel-Based Three-Dimensional Cultures of Mesenchymal Stromal Cells. Haematologica 2012, 97 (5), 651-660.
(94) Jing, D.; Fonseca, A. V.; Alakel, N.; Fierro, F. A.; Muller, K.; Bornhauser, M.; Ehninger, G.; Corbeil, D.; Ordemann, R. Hematopoietic Stem Cells in Co-Culture with Mesenchymal Stromal Cells -Modeling the Niche Compartments in Vitro. Haematologica 2010, 95 (4), 542-550.

(95) Abangan, R. S.; Williams, C. R.; Mehrotra, M.; Duncan, J. D.; Larue, A. C. MCP1 Directs Trafficking of Hematopoietic Stem CellDerived Fibroblast Precursors in Solid Tumor. Am. J. Pathol. 2010, 176 (4), 1914-1926.

(96) Si, Y.; Tsou, C.-L.; Croft, K.; Charo, I. F. CCR2 Mediates Hematopoietic Stem and Progenitor Cell Trafficking to Sites of Inflammation in Mice. J. Clin. Invest. 2010, 120 (4), 1192-1203.

(97) Sivori, S.; Cantoni, C.; Parolini, S.; Marcenaro, E.; Conte, R.; Moretta, L.; Moretta, A. IL-21 Induces Both Rapid Maturation of Human CD34 + Cell Precursors towards NK Cells and Acquisition of Surface Killer Ig-like Receptors. Eur. J. Immunol. 2003, 33 (12), 34393447.

(98) Ozaki, K.; Spolski, R.; Ettinger, R.; Kim, H.-P.; Wang, G.; Qi, C.F.; Hwu, P.; Shaffer, D. J.; Akilesh, S.; Roopenian, D. C.; Morse, H. C.; Lipsky, P. E.; Leonard, W. J. Regulation of B Cell Differentiation and Plasma Cell Generation by IL-21, a Novel Inducer of Blimp-1 and Bcl6. J. Immunol. 2004, 173 (9), 5361-5371.

(99) Crigler, L.; Robey, R. C.; Asawachaicharn, A.; Gaupp, D.; Phinney, D. G. Human Mesenchymal Stem Cell Subpopulations Express a Variety of Neuro-Regulatory Molecules and Promote Neuronal Cell Survival and Neuritogenesis. Exp. Neurol. 2006, 198 (1), 54-64.

(100) Shelton, D. L.; Reichardt, L. F. Expression of the $\beta$-Nerve Growth Factor Gene Correlates with the Density of Sympathetic Innervation in Effector Organs. Proc. Natl. Acad. Sci. U. S. A. 1984, 81 (24), 7951-7955.

(101) Choi, J. S.; Harley, B. A. C. The Combined Influence of Substrate Elasticity and Ligand Density on the Viability and Biophysical Properties of Hematopoietic Stem and Progenitor Cells. Biomaterials 2012, 33 (18), 4460-4468.

(102) Goloviznina, N. A.; Verghese, S. C.; Yoon, Y.; Taratula, O.; Marks, D. L.; Kurre, P. Mesenchymal Stromal Cell-Derived Extracellular Vesicles Promote Myeloid-Biased Multipotent Hematopoietic Progenitor Expansion via Toll-Like Receptor Engagement * Edited by Dennis Voelker. J. Biol. Chem. 2016, 291 (47), 2460724617.

(103) Walenda, T.; Bork, S.; Horn, P.; Wein, F.; Saffrich, R.; Diehlmann, A.; Eckstein, V.; Ho, A. D.; Wagner, W. Co-Culture with Mesenchymal Stromal Cells Increases Proliferation and Maintenance of Haematopoietic Progenitor Cells. J. Cell. Mol. Med. 2010, 14 (1-2), 337-350.

(104) Mehrasa, R.; Vaziri, H.; Oodi, A.; Khorshidfar, M.; Nikogoftar, M.; Golpour, M.; Amirizadeh, N. Mesenchymal Stem Cells as a Feeder Layer Can Prevent Apoptosis of Expanded Hematopoietic Stem Cells Derived from Cord Blood. Int. J. Mol. Cell. Med. 2014, 3 (1), 1-10.

(105) Zhang, Y.; Chai, C.; Jiang, X.-S.; Teoh, S.-H.; Leong, K. W. Coculture of Umbilical Cord Blood CD34+ Cells with Human Mesenchymal Stem Cells. Tissue Eng. 2006, 12 (8), 2161-2170.

(106) Manz, M. G.; Miyamoto, T.; Akashi, K.; Weissman, I. L. Prospective Isolation of Human Clonogenic Common Myeloid Progenitors. Proc. Natl. Acad. Sci. U. S. A. 2002, 99 (18), 1187211877 .

(107) Testa, U.; Pelosi, E.; Frankel, A. CD 123 Is a Membrane Biomarker and a Therapeutic Target in Hematologic Malignancies. Biomark. Res. 2014, 2 (1), 4.

(108) Galy, A.; Travis, M.; Cen, D.; Chen, B. Human T, B, Natural Killer, and Dendritic Cells Arise from a Common Bone Marrow Progenitor Cell Subset. Immunity 1995, 3, 459-473. 